\title{
The Optimal Pricing of Dual-Channel Supply Chain with the Third Party Product Recovery and Sales Effort
}

\author{
Limin Wang $\mathbb{D},{ }^{1}$ Qiankun Song $\mathbb{D}^{2}$, and Zhenjiang Zhao $\mathbb{D}^{3}$ \\ ${ }^{1}$ School of Economic and Management, Chongqing Jiaotong University, Chongqing 400074, China \\ ${ }^{2}$ Department of Mathematics, Chongqing Jiaotong University, Chongqing 400074, China \\ ${ }^{3}$ Department of Mathematics, Huzhou University, Huzhou 313000, China \\ Correspondence should be addressed to Qiankun Song; qiankunsong@163.com
}

Received 25 April 2020; Accepted 9 June 2020; Published 25 June 2020

Guest Editor: Xiaodi Li

Copyright ( $\odot 2020$ Limin Wang et al. This is an open access article distributed under the Creative Commons Attribution License, which permits unrestricted use, distribution, and reproduction in any medium, provided the original work is properly cited.

The optimal pricing of dual-channel supply chain with the third party product recovery and sales effort is considered in this paper. The optimal selling pricing of direct channel and retail channel in the forward supply chain and the optimal collection pricing of retail channel and the third party in the backward supply chain are given for the general case under the centralized and decentralized model. Then, the effect of sales effort of the retailer and the optimal pricing strategy with sales effort under the centralized and decentralized model are provided and analyzed. Finally, the comparative analysis of four situations is carried out by numerical results.

\section{Introduction}

In order to improve the utilization rate of resources and reduce environmental pollution, many enterprises are engaged in remanufacturing [1-4]. With the development of science and technology, products could be used for recycling and restoring their original function. Remanufacturing products could meet expectations of consumers on new products, at the same time, the process of remanufacturing could reduce resource consumption and emissions. Research has shown that, by implementing product remanufacturing strategy, enterprises can save the cost of $40 \%-65 \%$. This not only saves the raw materials of the new parts but also avoids the waste of the resource [5]. The China Daily reported on January 4, 2018, since China adopted the global ban on the import of waste, the European and American countries faced a garbage crisis. Therefore, recycling and remanufacturing becomes even more important. In addition, due to changes in consumer shopping habits and the environmental protection consciousness enhancement, more and more enterprises would see the remanufacturing as a strategy to expand market share, and many companies have established a remanufacturing system [6-12].
Companies such as Caterpillar, GE Aviation, and MercedesBenz have built remanufacturing plants in Shanghai.

Because the remanufacturing has very potent prospect, many independent manufacturers have focused on this area [13-20]. Many of construction equipment retailers are gradually implementing the remanufacturing strategy, as a result the remanufacturing has lower production cost. Therefore, it is one available strategy through discounts to attract consumers when facing competitive threat on the market [21]. It is widely believed that the remanufacturing market activities are more complex than the traditional production and the sales process. For many different characteristics of remanufacturing goods, such as the uncertain sources of the product of supply chain, the process involves the forward and reverse logistics [22]. Therefore, for those who are engaged in remanufacturing enterprise, how to build a profitable closed-loop supply chain to effectively recycle used products should be considered. On the contrary, the distribution of new products and remanufactured products is one of the pressing problems.

Results on remanufacturing recycling dual-channel are less researched in the existing literature. In [23], the presence of competing retailers is considered in the reverse channel. 
Recovery system on the management of manufacturers and retailers was modeled and studied. Huang et al. studied the optimal decision of dual recycling channels of the closedloop supply chain and put forward the macroeconomic regulation and control policy based on the numerical analysis. The authors discussed that the dual recycling channel is more effective than the single recycling channel for more manufacturers [24]. In [25], the authors studied the manufacturer-oriented three reverse-mixed recycling channels of the closed-loop supply chain structure, namely, the manufacturer and retailer mix recycling channels, manufacturer and third-party recycling channels, and retailer and third-party mix recycling channels, coming to a conclusion that the mixture of manufacturers and retailers is the most effective recycling channels.

In real life, the sales effort on the market has become a key factor in determining the selling price [26]. There are many approaches to improve the market demand for products through sales effort, such as providing the bigger shelf space, promotion, and advertising. Many research results about the effect of sales effort on achieving supply chain coordination. Ma et al. discussed the profits of retailer and manufacturer characteristics under different channel strategies and sales effort levels [27]. In [28], the authors predicted a supplier-retailer of agricultural supply chain, including market demand which depends on the sales effort, and provided service.

Based on the above analysis, this paper aims to study the optimal pricing of the dual-channel supply chain with the third-party product recovery and sales effort. First of all, for the general case under the centralized and decentralized model, discuss the optimal selling pricing of the direct channel and retail channel in the forward supply chain and the optimal collection pricing of the retail channel and the third party in the backward supply chain. Then, the optimal pricing strategy with sales effort under the centralized and decentralized model is provided and analyzed. Finally, the comparative analysis of four situations is carried out by numerical results.

The organizational structure of this paper is given as follows. Section 1 is the introduction of this paper; Section 2 is the model description of this paper; Section 3 studies the optimal selling pricing of the direct channel and retail channel in the forward supply chain and the optimal collection pricing of the retail channel and the third party in the backward supply chain; Section 4 discusses the centralized model and decentralized model with sales effort; Section 5 carries out the comparative analysis of four situations by numerical results; Section 6 summarizes the research of this paper.

\section{Model Description}

In this paper, we consider a kind of closed-loop supply chain with a dual channel which consists of three members: one manufacturer, one retailer, and one third party. As shown in Figure 1, in the forward supply chain, the manufacturer produces products at $\operatorname{cost} c_{r}$ and sells products to consumer by direct channel at price $p_{d}$. The manufacturer sells

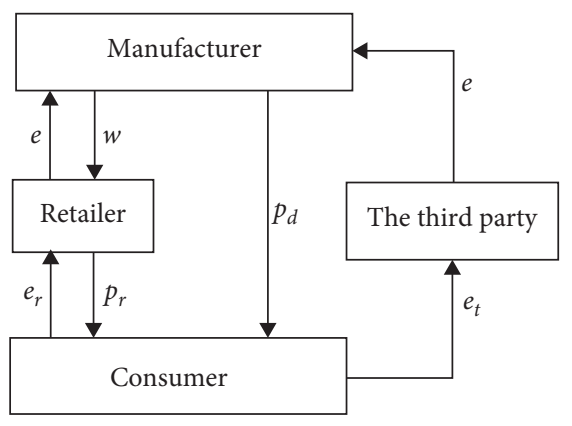

Figure 1: The structure of the whole supply chain system.

products to the retailer at wholesale price $w$ and the retailer sells products to the consumer by the retail channel at price $p_{r}$. In the reverse supply chain, the retailer and the third party collect the used products from the consumer at recycling prices $e_{r}$ and $e_{t}$, respectively. The manufacturer recycles the used products for remanufacturing from the retailer and the third party at recycling price of $e$.

The manufacturer should make a decision about the price of the direct channel and the wholesale price to the retailer, the retailer makes a decision about the price of the retail channel and the recycling price $e_{r}$, and the third party needs to consider the recycling price $e_{t}$ to maximize their own profits, respectively. Throughout this paper, the notations are given as Table 1.

To obtain the main results, we give the following assumptions.

Assumption 1. As mentioned in [29], the demand function is considered as one linear function on the direct selling price and retail selling price. Since the influence of the selfprice on demand should be larger than the influence of cross price, we assume that $b_{1}>b_{2}$.

Assumption 2. For the significance of remanufacturing, the unit produce cost of producing new products $c_{n}$ and unit produce cost of remanufacturing products $c_{r}$ should satisfy that $c_{r}+e \leq c_{n}$.

Assumption 3. Since that the profit of collecting products must be nonnegative for the retailer and third party to guarantee the effectiveness of recycle, there exists $e_{r} \leq e$ and $e_{t} \leq e$.

Assumption 4. Assume that the collection rate $\tau$ is a constant number, which means that, for the whole demand function $D, \tau D$ would be remanufactured products and $(1-\tau) D$ would be new manufactured products.

Assumption 5. In this paper, similar with the market demand functions, the collection functions for the retailer and the third party are considered as linear functions on their collection price. We assume that $\tau_{r}=(1-\alpha) \tau D+\beta_{1} e_{r}-$ $\beta_{1} e_{t}$ and $\tau_{t}=\alpha \tau \quad D+\beta_{1} e_{t}-\beta_{2} e_{r}$, where $\alpha$ represents the basic market share to the third party, $\alpha \tau D$ stands for the proportion of consumers' preference for the third party, and 
TABLE 1: Table of notations.

\begin{tabular}{lc}
\hline Notation & Meaning \\
\hline$i$ & $i=r, d, t$ stands for the retail channel, direct channel, and third party, respectively \\
$p_{i}$ & Unit selling price of channel $i, i=r, d$ \\
$e$ & The collection price from the retailer and third party \\
$e_{i}$ & The collection price from the consumer through channel $i, i=r, t$ \\
$w$ & The wholesale of nongreen product to the retailer \\
$s$ & Sales effort \\
$b_{1}$ & Self-price demand elasticity coefficient \\
$b_{2}$ & Cross-price demand elasticity coefficient \\
$\tau$ & Collection rate of products \\
$\tau_{i}$ & Collection demand of channel $i, i=r, t$ \\
$\beta_{i}$ & Collection demand elasticity coefficient, $i=1,2$ \\
$c_{n}$ & Unit produce cost of producing new products \\
$c_{r}$ & Unit produce cost of remanufacturing products \\
\hline
\end{tabular}

$(1-\alpha) \tau \quad D$ stands for the proportion of consumers' preference for the retail channel so that $\tau_{r}+\tau_{t}=\tau \quad D+\left(\beta_{1}-\beta_{2}\right)\left(e_{r}+e_{t}\right)$.

Assumption 6. According to [30], we assume that the collection cost is considered as the quadratic function of the collection rate, which is considered as $(1 / 2) k \tau_{i}^{2}$ for $i=r, t$.

Based on Assumption 1, the demand functions of the retail channel and direct channel are expressed as linear functions of self-price, cross price, and market scale, which are, respectively, shown as follows:

$$
\begin{aligned}
& D_{r}=D_{1}-b_{1} p_{r}+b_{2} p_{d}, \\
& D_{d}=D_{2}-b_{1} p_{d}+b_{2} p_{r},
\end{aligned}
$$

where $D_{1}$ stands for the proportion of consumers' preference for the retail channel and $D_{2}$ stands for the proportion of consumers' preference for the direct channel.

According to Assumption 5, the collection demand functions of the retail channel and third party channel are expressed as linear functions of self-collecting price, cross- collecting price, and collecting rate, which are, respectively, shown as follows:

$$
\begin{aligned}
& \tau_{r}=(1-\alpha) \tau \quad D+\beta_{1} e_{r}-\beta_{2} e_{t}, \\
& \tau_{t}=\alpha \tau \quad D+\beta_{1} e_{t}-\beta_{2} e_{r},
\end{aligned}
$$

where $D=D_{1}+D_{2}$ stands for the potential whole market demand.

Accordingly, based on the above assumptions and demand functions, the profit function of the retailer is considered as follows:

$$
\pi_{r}\left(p_{r}, e_{r}\right)=D_{r}\left(p_{r}-w\right)+\tau_{r}\left(e-e_{r}\right)-\frac{1}{2} k \tau_{r}^{2},
$$

where $D_{r}\left(p_{r}-w\right)$ stands for the profit of selling products to the consumer by the retail channel and $\tau_{r}\left(e-e_{r}\right)$ represents the profit of collecting products from the manufacturer. The collection cost is considered as $(1 / 2) k \tau_{r}^{2}$.

Denote that the unit produce cost of remanufacturing products is $c_{r}$; then, the profit function of the manufacturer is given by

$$
\begin{aligned}
& \pi_{d}\left(w, p_{d}\right)=D_{r} w+D_{d} p_{d}-\left[(1-\tau) D-\left(\beta_{1}-\beta_{2}\right)\left(e_{r}+e_{t}\right)\right] c_{n}-\left[\tau \quad D+\left(\beta_{1}-\beta_{2}\right)\left(e_{r}+e_{t}\right)\right]\left(c_{r}+e\right) \\
& \pi_{t}\left(e_{t}\right)=\tau_{t}\left(e-e_{t}\right)-\frac{1}{2} k \tau_{t}^{2} .
\end{aligned}
$$

where the $D_{r} w$ and $D_{d} p_{d}$ represents the profit of selling products to the consumer by the retail channel and direct channel, respectively. $\left[(1-\tau) D-\left(\beta_{1}-\beta_{2}\right)\left(e_{r}+e_{t}\right)\right] c_{n}$ denotes the producing cost for new products and $\left[\begin{array}{ll}\tau & D+\end{array}\right.$ $\left.\left(\beta_{1}-\beta_{2}\right)\left(e_{r}+e_{t}\right)\right]\left(c_{r}+e\right)$ stands for the recycling and remanufacturing cost for the collected products.

The collection cost of the third party is considered as $(1 / 2) k \tau_{r}^{2}$ so that the profit function of the third party is presented as 


$$
\begin{aligned}
& \pi_{s c}\left(p_{r}, p_{d}, e_{r}, e_{t}\right)=D_{r} p_{r}+D_{d} p_{d}+\left(\beta_{1}-\beta_{2}\right)\left(e_{r}+e_{t}\right)\left(c_{n}-c_{r}\right)-(1-\tau) D c_{n} \\
& -\tau \quad D c_{r}-\tau_{r} e_{r}-\tau_{t} e_{t}-\frac{1}{2} k \tau_{r}^{2}-\frac{1}{2} k \tau_{t}^{2} \\
& =\left(D_{1}-b_{1} p_{r}+b_{2} p_{d}\right) p_{r}+\left(D_{2}-b_{1} p_{d}+b_{2} p_{r}\right) p_{d}+\left(\beta_{1}-\beta_{2}\right)\left(e_{r}+e_{t}\right)\left(c_{n}-c_{r}\right) \\
& -(1-\tau) D c_{n}-\tau \quad D c_{r}-\left[(1-\alpha) \tau \quad D+\beta_{1} e_{r}-\beta_{2} e_{t}\right] e_{r}-\left(\alpha \tau \quad D+\beta_{1} e_{t}-\beta_{2} e_{r}\right) e_{t}
\end{aligned}
$$

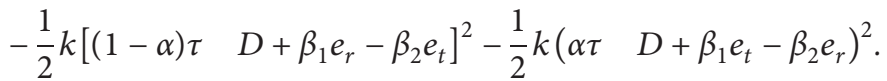

Proposition 1. When the market is under centralized situation, if the parameters satisfy that $\left(2 \beta_{1}+k \beta_{1}^{2}+k \beta_{2}^{2}\right)-2 \beta_{2}\left(1+k \beta_{1}\right)>0$, then there exists the unique optimal solution:

$$
\begin{aligned}
& p_{r}^{c 1 *}=\frac{b_{1} D_{1}+b_{2} D_{2}}{2\left(b_{1}^{2}-b_{2}^{2}\right)}, \\
& p_{d}^{c 1 *}=\frac{b_{2} D_{1}+b_{1} D_{2}}{2\left(b_{1}^{2}-b_{2}^{2}\right)}, \\
& e_{r}^{c 1 *}=\frac{\left(2 \beta_{1}+k \beta_{1}^{2}+k \beta_{2}^{2}\right)\left[\left(\beta_{1}-\beta_{2}\right)\left(c_{n}-c_{r}\right)+k \beta_{2} \alpha \tau \quad D-\left(1+k \beta_{1}\right)(1-\alpha) \tau \quad D\right]+2 \beta_{2}\left(1+k \beta_{1}\right)\left[\left(\beta_{1}-\beta_{2}\right)\left(c_{n}-c_{r}\right)+k \beta_{2}(1-\alpha) \tau\right.}{\left(2 \beta_{1}+k \beta_{1}^{2}+k \beta_{2}^{2}\right)^{2}-4 \beta_{2}^{2}\left(1+k \beta_{1}\right)^{2}},
\end{aligned}
$$

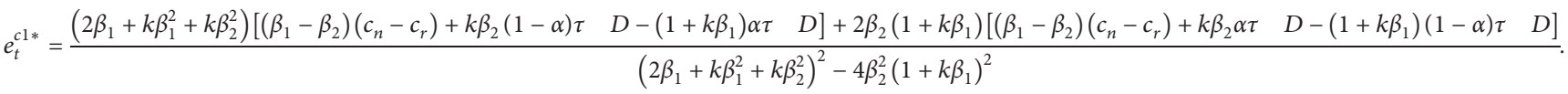

Proof. According to the profit function of whole supply chain (6), taking the first-order derivatives of $\pi_{s c}\left(p_{r}, p_{d}, e_{r}, e_{t}\right)$ along the retail price $p_{r}$, the direct price $p_{d}$, the collecting price of retailer $e_{r}$, and the collecting price of the third party $e_{t}$, we could obtain

$$
\begin{aligned}
& \frac{\partial \pi_{s c}\left(p_{r}, p_{d}, e_{r}, e_{t}\right)}{\partial p_{r}}=-2 b_{1} p_{r}+2 b_{2} p_{d}+D_{1}, \\
& \frac{\partial \pi_{s c}\left(p_{r}, p_{d}, e_{r}, e_{t}\right)}{\partial p_{d}}=2 b_{2} p_{r}-2 b_{1} p_{d}+D_{2}, \\
& \frac{\partial \pi_{s c}\left(p_{r}, p_{d}, e_{r}, e_{t}\right)}{\partial e_{r}}=-\left(2 \beta_{1}+k \beta_{1}^{2}+k \beta_{2}^{2}\right)+2 \beta_{2}\left(1+k \beta_{1}\right) e_{t}+\left(\beta_{1}-\beta_{2}\right)\left(c_{n}-c_{r}\right)+k \beta_{2} \alpha \tau \quad D-\left(1+k \beta_{1}\right)(1-\alpha) \tau \quad D, \\
& \frac{\partial \pi_{s c}\left(p_{r}, p_{d}, e_{r}, e_{t}\right)}{\partial e_{t}}=2 \beta_{2}\left(1+k \beta_{1}\right) e_{r}-\left(2 \beta_{1}+k \beta_{1}^{2}+k \beta_{2}^{2}\right) e_{t}+\left(\beta_{1}-\beta_{2}\right)\left(c_{n}-c_{r}\right)+k \beta_{2}(1-\alpha) \tau \quad D-\left(1+k \beta_{1}\right) \alpha \tau \quad D .
\end{aligned}
$$

Hence, the Hessian matrix is given as

$$
H^{c 1}=\left(\begin{array}{cccc}
-2 b_{1} & 2 b_{2} & 0 & 0 \\
2 b_{2} & -2 b_{1} & 0 & 0 \\
0 & 0 & -2 \beta_{1}-k \beta_{1}^{2}-k \beta_{2}^{2} & 2 \beta_{2}\left(1+k \beta_{1}\right) \\
0 & 0 & 2 \beta_{2}\left(1+k \beta_{1}\right) & -2 \beta_{1}-k \beta_{1}^{2}-k \beta_{2}^{2}
\end{array}\right) .
$$


Obviously, the second derivative satisfies that $\partial^{2} \pi_{s c}\left(p_{r}\right.$, $\left.p_{d}, e_{r}, e_{t}\right) / \partial p_{r}^{2}=\partial^{2} \pi_{s c}\left(p_{r}, p_{d}, e_{r}, e_{t}\right) / \partial p_{d}^{2}=-2 b_{1}<0$. Based on the condition of proposition, $\left(2 \beta_{1}+k \beta_{1}^{2}+k \beta_{2}^{2}\right)-2 \beta_{2}\left(1+k \beta_{1}\right)>0$, it could be obtained that $\left(2 \beta_{1}+k \beta_{1}^{2}+k \beta_{2}^{2}\right)^{2}-4 \beta_{2}^{2}\left(1+k \beta_{1}\right)^{2}>0$. Therefore, the profit function $\pi_{s c}\left(p_{r}, p_{d}, e_{r}, e_{t}\right)$ is joint concave on $p_{r}, p_{d}$, $e_{r}$, and $e_{t}$. The optimal solution could be obtained by solving the first-order condition. The proof is completed.

Remark 1. Proposition 1 shows the optimal solution under centralized situation. According to the result of Proposition 1 , it could be concluded that the retail selling price and direct selling price are related with the values of $D_{1}$ and $D_{2}$. Under the assumption that $D_{1}=(1-\rho) a$ and $D_{2}=\rho a$, we could find $p_{r}^{c *}>p_{d}^{c *}$ if $0<\rho<0.5$ and $p_{r}^{c *}<p_{d}^{c *}$ if $0.5<\rho<1$. It demonstrates that the channel has higher selling price when the channel occupies higher market share. Furthermore, if $\quad \alpha=0.5$, then $e_{r}^{c 1 *}=e_{t}^{c 1 *}=\left(\left(2 \beta_{1}+k \beta_{1}^{2}+k \beta_{2}^{2}+2 \beta_{2}\right.\right.$ $\left.\left(1+k \beta_{1}\right)\right)\left[\left(\beta_{1}-\beta_{2}\right)\left(c_{n}-c_{r}\right)+0.5 k \beta_{2} \tau \quad D-0.5\left(1+k \beta_{1}\right)\right.$ $\left.\tau D] /\left(2 \beta_{1}+k \beta_{1}^{2}+k \beta_{2}^{2}\right)^{2}-4 \beta_{2}^{2}\left(1+k \beta_{1}\right)^{2}\right)$. It shows that, under the centralized decision model, if the potential demand of the retailer and the third party for the recycled products was equal, there is no competitive relationship on the behavior of the recycled products, and the price of the recycled products is consistent.

3.2. Decentralized Model. This section considers that manufacturers, retailers, and third parties, respectively, make sales pricing decisions and collection pricing decisions to maximize their respective profits. Consider the supply chain under the manufacturer-led Stackelberg model. According to the profit function of retailer (3), profit function of manufacturer (4), and profit function of third party (5), it has

$$
\begin{aligned}
& \pi_{r}\left(p_{r}, e_{r}\right)=\left(D_{1}-b_{1} p_{r}+b_{2} p_{d}\right)\left(p_{r}-w\right)+\left[\begin{array}{ll}
1-\alpha) \tau & D+\beta_{1} e_{r}-\beta_{2} e_{t}
\end{array}\right]\left(e-e_{r}\right)-\frac{1}{2} k\left[\begin{array}{ll}
1-\alpha) \tau & D+\beta_{1} e_{r}-\beta_{2} e_{t}
\end{array}\right]^{2}, \\
& \pi_{d}\left(p_{d}, w\right)=\left(D_{1}-b_{1} p_{r}+b_{2} p_{d}\right) w+\left(D_{2}-b_{1} p_{r}+b_{2} p_{d}\right) p_{d}+\left(\beta_{1}-\beta_{2}\right)\left(c_{n}-c_{r}-e\right)\left(e_{r}+e_{t}\right)-(1-\tau) D c_{n}-\tau \quad D\left(c_{r}+e\right) \\
& \pi_{t}\left(e_{t}\right)=\left(\begin{array}{ll}
\alpha \tau & D+\beta_{1} e_{t}-\beta_{2} e_{r}
\end{array}\right)\left(e-e_{t}\right)-\frac{1}{2} k\left(\alpha \tau \quad D+\beta_{1} e_{t}-\beta_{2} e_{r}\right)^{2}
\end{aligned}
$$

Proposition 2. When the market is under decentralized situation, if the parameters of supply chain (10)-(12) satisfy the condition of $\beta_{1}^{2}\left(2+k \beta_{1}\right)^{2}-\beta_{2}^{2}\left(1+k \beta_{1}\right)^{2}>0$, then there exists the unique optimal solution:

$$
\begin{aligned}
& p_{r}^{d 1 *}=\frac{3 b_{1}^{2} D_{1}-b_{2}^{2} D_{1}+2 b_{1} b_{2} D_{2}}{4 b_{1} D_{1}\left(b_{1}^{2}-b_{2}^{2}\right)} \\
& p_{d}^{d 1 *}=\frac{b_{2} D_{1}+b_{1} D_{2}}{2\left(b_{1}^{2}-b_{2}^{2}\right)}
\end{aligned}
$$

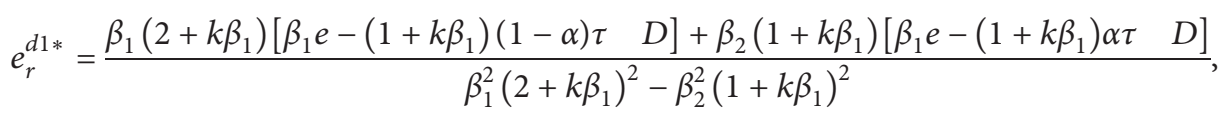

$$
\begin{aligned}
& e_{t}^{d 1 *}=\frac{\beta_{1}\left(2+k \beta_{1}\right)\left[\beta_{1} e-\left(1+k \beta_{1}\right) \alpha \tau \quad D\right]+\beta_{2}\left(1+k \beta_{1}\right)\left[\beta_{1} e-\left(1+k \beta_{1}\right)(1-\alpha) \tau \quad D\right.}{\beta_{1}^{2}\left(2+k \beta_{1}\right)^{2}-\beta_{2}^{2}\left(1+k \beta_{1}\right)^{2}} \text {. }
\end{aligned}
$$

Proof. For the retailer and the third party, according to the profit functions of the retailer and the third party (10) and (12), taking the first-order derivatives of $\pi_{r}\left(p_{r}, e_{r}\right)$ and $\pi_{t}\left(e_{t}\right)$ along the retail price $p_{r}$, the collecting price of retailer $e_{r}$, and the collecting price of the third party $e_{t}$, respectively, we could obtain 


$$
\begin{aligned}
& \frac{\partial \pi_{r}\left(p_{r}, e_{r}\right)}{\partial p_{r}}=-2 b_{1} p_{r}+b_{2} p_{d}+b_{1} w+D_{1}, \\
& \frac{\partial \pi_{r}\left(p_{r}, e_{r}\right)}{\partial e_{r}}=-\beta_{1}\left(2+k \beta_{1}\right) e_{r}+\beta_{2}\left(1+k \beta_{1}\right) e_{t}+\beta_{1} e-\left(1+k \beta_{1}\right)(1-\alpha) \tau \quad D, \\
& \frac{\partial \pi_{t}\left(e_{t}\right)}{\partial e_{t}}=\beta_{2}\left(1+k \beta_{1}\right) e_{r}-\beta_{1}\left(2+k \beta_{1}\right) e_{t}+\beta_{1} e-\left(1+k \beta_{1}\right) \alpha \tau \quad D .
\end{aligned}
$$

Hence, the Hessian matrix is given as

$$
H^{d 1}=\left(\begin{array}{ccc}
-2 b_{1} & 0 & 0 \\
0 & -\beta_{1}\left(2+k \beta_{1}\right) & \beta_{2}\left(1+k \beta_{1}\right) \\
0 & \beta_{2}\left(1+k \beta_{1}\right) & -\beta_{1}\left(2+k \beta_{1}\right)
\end{array}\right) .
$$

Obviously, the second derivative satisfies that $\left(\partial^{2} \pi_{r}\left(p_{r}, e_{r}\right) / \partial p_{r}^{2}\right)=-2 b_{1}<0$ and $\left(\partial^{2} \pi_{t}\left(e_{t}\right) / \partial e_{t}^{2}\right)=\left(\partial^{2} \pi_{r}\right.$ $\left.\left(p_{r}, e_{r}\right) / \partial e_{r}^{2}\right)=-\beta_{1}\left(2+k \beta_{1}\right)<0$. Based on the condition of proposition, $\beta_{1}^{2}\left(2+k \beta_{1}\right)^{2}-\beta_{2}^{2}\left(1+k \beta_{1}\right)^{2}>0$. Therefore, the profit functions $\pi_{r}\left(p_{r}, e_{r}\right)$ and $\pi_{t}\left(e_{t}\right)$ are joint concave on $p_{r}$, $e_{r}$, and $e_{t}$. The optimal solution could be obtained by solving the first-order condition as follows:

$$
\begin{aligned}
& p_{r}^{d 1 *}=\frac{1}{2 b_{1}}\left(b_{2} p_{d}+b_{1} w+D_{1}\right)
\end{aligned}
$$

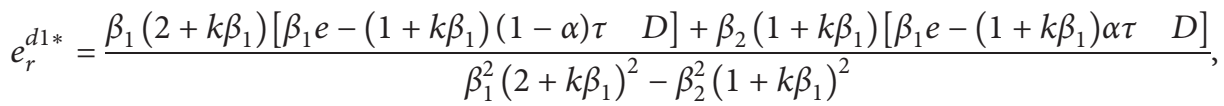

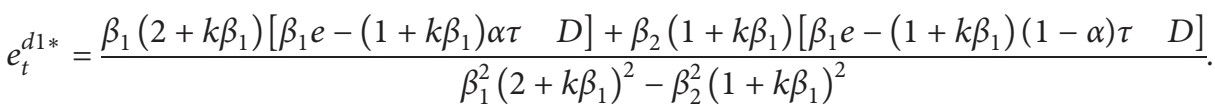

Substitute the $p_{r}^{d 1 *}, e_{r}^{d 1 *}$, and $e_{t}^{d 1 *}$ into profit function (10), and it obtains

$$
\begin{aligned}
\pi_{d}\left(p_{d}, w\right)= & {\left[D_{2}-b_{1} p_{d}+\frac{b_{2}}{2 b_{1}}\left(b_{2} p_{d}+b_{1} w+D_{1}\right)\right] p_{d}+\frac{1}{2}\left(b_{2} p_{d}+b_{1} w+D_{1}\right) w } \\
& +\left(\beta_{1}-\beta_{2}\right)\left(c_{n}-c_{r}-e\right)\left(e_{r}+e_{t}\right)-(1-\tau) D c_{n}-\tau \quad D\left(c_{r}+e\right) .
\end{aligned}
$$

For the manufacturer, taking the first-order derivatives of $\pi_{d}\left(p_{d}, w\right)$ along the direct price $p_{d}$ and wholesale price $w$, we could obtain

$$
\begin{aligned}
& \frac{\partial \pi_{d}\left(p_{d}, w\right)}{\partial p_{d}}=\left(-2 b_{1}+\frac{b_{2}^{2}}{b_{1}}\right) p_{d}+b_{2} w+D_{2}+\frac{b_{2} D_{1}}{2 b_{1}}, \\
& \frac{\partial \pi_{d}\left(p_{d}, w\right)}{\partial w}=b_{2} p_{d}-b_{1} w+\frac{D_{1}}{2} .
\end{aligned}
$$

The Hessian matrix is given as

$$
H_{1}^{d 1}=\left(\begin{array}{cc}
-2 b_{1}+\frac{b_{2}^{2}}{b_{1}} & b_{2} \\
b_{2} & -b_{1}
\end{array}\right) .
$$

Obviously, the second derivative satisfies that $\left(\partial^{2} \pi_{d}\left(p_{d}, w\right) / \partial p_{d}^{2}\right)=-2 b_{1}+\left(b_{2}^{2} / b_{1}\right)<0, \quad\left(\partial^{2} \pi_{d}\left(p_{d}, w\right) /\right.$ $\left.\partial w^{2}\right)=-b_{1}<0$, and $\left|H_{1}^{d 1}\right|=2\left(b_{1}^{2}-b_{2}^{2}\right)>0$. Therefore, the profit function $\pi_{d}\left(p_{d}, w\right)$ is joint concave on $p_{d}$ and $w$. The optimal solution could be obtained by solving the first-order condition as follows:

$$
\begin{aligned}
p_{d}^{d 1 *} & =\frac{b_{2} D_{1}+b_{1} D_{2}}{2\left(b_{1}^{2}-b_{2}^{2}\right)}, \\
w^{1 *} & =\frac{b_{2}^{2} D_{1}+b_{1} b_{2} D_{2}}{2 b_{1}\left(b_{1}^{2}-b_{2}^{2}\right)}+\frac{D_{1}}{2 b_{1}} .
\end{aligned}
$$

The proof is completed.

According to the conclusion of Proposition 2, in the decentralized model, the wholesale price of the 
manufacturer to retailers is the same as the retail selling price of traditional channels in the centralized model, that is, $w^{2 *}=p_{r}^{c 1 *}$, which leads to higher selling prices for retailers under the decentralized model. As for the collection price, the result shows the collection price under the centralized model is higher than the collection price under decentralized model for $e_{r}^{c 1 *}>e_{r}^{d 1 *}$ and $e_{t}^{c 1 *}>e_{t}^{d 1 *}$.

\section{The Optimization on Sales Effort}

The decision on sales effort of the retailer is considered in this section. In practical application, the sales effort on the market has become a key factor of the retail price. More examples show that the demand function depends on sales effort. Taylor points out that the retailer's sales effort service (mainly sales work, includes providing space or shelf space, promotion, and advertising) increases the demand for products, and the results demonstrated how to realize supply chain coordination through the sales and service effect [26]. Therefore, this section discusses and compares the optimal pricing and optimal profit with sales effort of the retailer.

Denote the sales effort of the retailer as $s$; then, the demand functions of dual channels are expressed as follows:

$$
\begin{aligned}
& \widehat{D}_{r}=D_{1}-b_{1} p_{r}+b_{2} p_{d}+g_{1} s, \\
& \widehat{D}_{d}=D_{2}-b_{1} p_{d}+b_{2} p_{r}+g_{2} s .
\end{aligned}
$$

Based on the demand functions, the profit function of the retailer is

$$
\widehat{\pi}_{r}\left(p_{r}, e_{r}\right)=\widehat{D}_{r}\left(p_{r}-w\right)+\widehat{\tau}_{r}\left(e-e_{r}\right)-\frac{1}{2} k \widehat{\tau}^{2}-\frac{1}{2} \eta s^{2},
$$

where $\widehat{D}_{r}\left(p_{r}-w\right)$ is the profit of selling products by the retail channel and $\widehat{\tau}_{r}\left(e-e_{r}\right)$ is the profit of collection products from consumers, $(1 / 2) k \widehat{\tau}_{r}^{2}$ is the cost of collection products, and $(1 / 2) \eta s^{2}$ is the cost of sales effort.

The profit function of the manufacturer is

$$
\widehat{\pi}_{d}\left(w, p_{d}\right)=\widehat{D}_{r} w+\widehat{D}_{d} p_{d}+\left(\beta_{1}-\beta_{2}\right)\left(c_{n}-c_{r}-e\right)\left(e_{r}+e_{t}\right)-(1-\tau) D c_{n}-\tau \quad D\left(c_{r}+e\right)
$$

where $\widehat{D}_{r} w$ is the profit of the retail channel, $\widehat{D}_{d} p_{d}$ is the profit of the direct channel, $(1-\tau) D c_{n}$ is the production cost of the new product, and $\tau \quad D\left(c_{r}+e\right)$ is the production cost of the remanufactured product. The profit function of the third party is

$$
\pi_{t}\left(e_{t}\right)=\tau_{t}\left(e-e_{t}\right)-\frac{1}{2} k \tau_{t}^{2} .
$$

4.1. Centralized Model with Sales Effort. According to the profit functions of the retailer, manufacturer, and third party (22)-(24), the profit of the whole supply chain is expressed as

$$
\begin{aligned}
& \widehat{\pi}_{s c}\left(p_{r}, p_{d}, e_{r}, e_{t}\right)=D_{r} p_{r}+D_{d} p_{d}+\left(\beta_{1}-\beta_{2}\right)\left(c_{n}-c_{r}\right)\left(e_{r}+e_{t}\right)-(1-\tau) D c_{n} \\
& -\tau \quad D c_{r}-\tau_{r} e_{r}-\tau_{t} e_{t}-\frac{1}{2} k \tau_{r}^{2}-\frac{1}{2} k \tau_{t}^{2} \\
& =\left(D_{1}-b_{1} p_{r}+b_{2} p_{d}+g_{1} s\right) p_{r}+\left(D_{2}-b_{1} p_{d}+b_{2} p_{r}+g_{2} s\right) p_{d} \\
& -(1-\tau) D c_{n}-\tau \quad D c_{r}-\left[(1-\alpha) \tau \quad D+\beta_{1} e_{r}-\beta_{2} e_{t}\right] e_{r}
\end{aligned}
$$

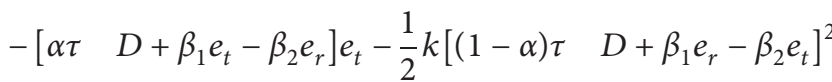

$$
\begin{aligned}
& -\frac{1}{2} k\left[\alpha \tau \quad D+\beta_{1} e_{t}-\beta_{2} e_{r}\right]^{2}-\frac{1}{2} \eta s^{2} .
\end{aligned}
$$


Proposition 3. When the market is under centralized situation with sales effort, if the parameters of (25) satisfy that $2 b_{1}^{2} \eta-2 b_{2} g_{1} g_{2}-b_{1}\left(g_{1}^{2}+g_{2}^{2}\right)-2 b_{2}^{2} \eta>0$, then there exists the unique optimal solution under the centralized model with sales effort:

$$
\begin{aligned}
& p_{r}^{c 2 *}=\frac{b_{1} D_{1}+b_{2} D_{2}}{2\left(b_{1}^{2}-b_{2}^{2}\right)}+\frac{\left(b_{1} g_{1}+b_{2} g_{2}\right)\left[\left(b_{1} D_{1}+b_{2} D_{2}\right) g_{1}+\left(b_{1} D_{2}+b_{2} D_{1}\right) g_{2}\right]}{2\left(b_{1}^{2}-b_{2}^{2}\right)\left[2 \eta\left(b_{1}^{2}-b_{2}^{2}\right)-\left(b_{1} g_{1}+b_{2} g_{2}\right) g_{1}-\left(b_{1} g_{2}+b_{2} g_{1}\right) g_{2}\right]}, \\
& p_{d}^{c 2 *}=\frac{b_{1} D_{2}+b_{2} D_{1}}{2\left(b_{1}^{2}-b_{2}^{2}\right)}+\frac{\left(b_{1} g_{2}+b_{2} g_{1}\right)\left[\left(b_{1} D_{1}+b_{2} D_{2}\right) g_{1}+\left(b_{1} D_{2}+b_{2} D_{1}\right) g_{2}\right]}{2\left(b_{1}^{2}-b_{2}^{2}\right)\left[2 \eta\left(b_{1}^{2}-b_{2}^{2}\right)-\left(b_{1} g_{1}+b_{2} g_{2}\right) g_{1}-\left(b_{1} g_{2}+b_{2} g_{1}\right) g_{2}\right]}, \\
& e_{r}^{c 2 *}=\frac{\left(\begin{array}{lll}
\left.2 \beta_{1}+k \beta_{1}^{2}+k \beta_{2}^{2}\right)\left[\left(\beta_{1}-\beta_{2}\right)\left(c_{n}-c_{r}\right)+k \beta_{2} \alpha \tau\right. & D-\left(1+k \beta_{1}\right)(1-\alpha) \tau & D
\end{array}\right]+2 \beta_{2}\left(1+k \beta_{1}\right)\left[\left(\beta_{1}-\beta_{2}\right)\left(c_{n}-c_{r}\right)+k \beta_{2}(1-\alpha) \tau\right.}{\left(2 \beta_{1}+k \beta_{1}^{2}+k \beta_{2}^{2}\right)^{2}-4 \beta_{2}^{2}\left(1+k \beta_{1}\right)^{2}}, \\
& e_{t}^{c 2 *}=\frac{\left(\begin{array}{lll}
\left.2 \beta_{1}+k \beta_{1}^{2}+k \beta_{2}^{2}\right)\left[\left[\begin{array}{lll}
\left(\beta_{1}-\beta_{2}\right)\left(c_{n}-c_{r}\right)+k \beta_{2}(1-\alpha) \tau & D-\left(1+k \beta_{1}\right) \alpha \tau & D
\end{array}\right]+2 \beta_{2}\left(1+k \beta_{1}\right)\left[\left(\beta_{1}-\beta_{2}\right)\left(c_{n}-c_{r}\right)+k \beta_{2} \alpha \tau\right.\right. & D-\left(1+k \beta_{1}\right)(1-\alpha) \tau & D
\end{array}\right]}{\left(2 \beta_{1}+k \beta_{1}^{2}+k \beta_{2}^{2}\right)^{2}-4 \beta_{2}^{2}\left(1+k \beta_{1}\right)^{2}}, \\
& s^{c 2 *}=\frac{\left(b_{1} D_{1}+b_{2} D_{2}\right) g_{1}+\left(b_{1} D_{2}+b_{2} D_{1}\right) g_{2}}{2 \eta\left(b_{1}^{2}-b_{2}^{2}\right)-\left(b_{1} g_{1}+b_{2} g_{2}\right) g_{1}-\left(b_{1} g_{2}+b_{2} g_{1}\right) g_{2}} .
\end{aligned}
$$

Proof. According to the profit function of the whole supply chain with sales effort (25), taking the first-order derivatives of $\hat{\pi}_{s c}\left(p_{r}, p_{d}, e_{r}, e_{t}, s\right)$ along the retail price $p_{r}$, the direct price $p_{d}$, the collecting price of retailer $e_{r}$, the collecting price of the third party $e_{t}$, and the sales effort $s$, we could obtain

$$
\begin{aligned}
& \frac{\partial \widehat{\pi}_{s c}\left(p_{r}, p_{d}, e_{r}, e_{t}, s\right)}{\partial p_{r}}=-2 b_{1} p_{r}+2 b_{2} p_{d}+d_{1}+g_{1} s \\
& \frac{\partial \widehat{\pi}_{s c}\left(p_{r}, p_{d}, e_{r}, e_{t}, s\right)}{\partial p_{d}}=2 b_{2} p_{r}-2 b_{1} p_{d}+d_{2}+g_{2} s \\
& \frac{\partial \widehat{\pi}_{s c}\left(p_{r}, p_{d}, e_{r}, e_{t}, s\right)}{\partial s}=g_{1} p_{r}+g_{2} p_{d}-\eta s \\
& \frac{\partial \widehat{\pi}_{s c}\left(p_{r}, p_{d}, e_{r}, e_{t}, s\right)}{\partial e_{r}}=-\left(2 \beta_{1}+k \beta_{1}^{2}+k \beta_{2}^{2}\right) e_{r}+2 \beta_{2}\left(1+k \beta_{1}\right) e_{t}+\left(\beta_{1}-\beta_{2}\right)\left(c_{n}-c_{r}\right)+k \beta_{2} \alpha \tau \quad D-\left(1+k \beta_{1}\right)(1-\alpha) \tau \quad D, \\
& \frac{\partial \widehat{\pi}_{s c}\left(p_{r}, p_{d}, e_{r}, e_{t}, s\right)}{\partial e_{t}}=2 \beta_{2}\left(1+k \beta_{1}\right) e_{r}-\left(2 \beta_{1}+k \beta_{1}^{2}+k \beta_{2}^{2}\right) e_{t}+\left(\beta_{1}-\beta_{2}\right)\left(c_{n}-c_{r}\right)+k \beta_{2}(1-\alpha) \tau \quad D-\left(1+k \beta_{1}\right) \alpha \tau \quad D .
\end{aligned}
$$

Hence, the Hessian matrix is given as

$$
H^{c 2}=\left(\begin{array}{ccc}
-2 b_{1} & 2 b_{2} & g_{1} \\
2 b_{2} & -2 b_{1} & g_{2} \\
g_{1} & g_{2} & -\eta
\end{array}\right) \text {. }
$$

Obviously, the second derivative satisfies that $\left(\partial^{2} \widehat{\pi}_{s c}\left(p_{r}, p_{d}, e_{r}, e_{t}, s\right) / \partial p_{r}^{2}\right)=\left(\partial^{2} \widehat{\pi}_{s c}\left(p_{r}, p_{d}, e_{r}, e_{t}, s\right) / \partial p_{d}^{2}\right)=$ $-2 b_{1}<0$ and $\left(\partial^{2} \widehat{\pi}_{s c}\left(p_{r}, p_{d}, e_{r}, e_{t}\right) / \partial s^{2}\right)=-\eta<0$. Based on the condition of proposition, $4 b_{2}\left(2 \beta_{1}+k \beta_{1}^{2}+\right.$ $\left.k \beta_{2}^{2}\right)-2 \beta_{2}\left(1+k \beta_{1}\right)>0$, it could be obtained that $\left|H^{c 2}\right|=-4 b_{1}^{2} \eta+4 b_{2} g_{1} g_{2}+2 b_{1}\left(g_{1}^{2}+g_{2}^{2}\right)+4 b_{2}^{2} \eta<0$. Therefore, the profit function $\widehat{\pi}_{s c}\left(p_{r}, p_{d}, e_{r}, e_{t}, s\right)$ is joint concave on $p_{r}, p_{d}, e_{r}, e_{t}$, and $s$. The optimal solution could be obtained by solving the first-order condition:

$$
\begin{aligned}
& p_{r}^{c 2 *}=\frac{b_{1} D_{1}+b_{2} D_{2}}{2\left(b_{1}^{2}-b_{2}^{2}\right)}+\frac{b_{1} g_{1}+b_{2} g_{2}}{2\left(b_{1}^{2}-b_{2}^{2}\right)} s^{c 2 *}, \\
& p_{d}^{c 2 *}=\frac{b_{1} D_{2}+b_{2} D_{1}}{2\left(b_{1}^{2}-b_{2}^{2}\right)}+\frac{b_{1} g_{2}+b_{2} g_{1}}{2\left(b_{1}^{2}-b_{2}^{2}\right)} s^{c 2 *}, \\
& s^{c 2 *}=\frac{\left(b_{1} D_{1}+b_{2} D_{2}\right) g_{1}+\left(b_{1} D_{2}+b_{2} D_{1}\right) g_{2}}{2 \eta\left(b_{1}^{2}-b_{2}^{2}\right)-\left(b_{1} g_{1}+b_{2} g_{2}\right) g_{1}-\left(b_{1} g_{2}+b_{2} g_{1}\right) g_{2}} .
\end{aligned}
$$

The proof is completed.

According to Propositions 1 and 3, the optimal solution of the centralized model with and without sales effort could be obtained: 


$$
\begin{aligned}
& p_{r}^{c 2 *}-p_{r}^{c 1 *}=\frac{\left(b_{1} g_{1}+b_{2} g_{2}\right)\left[\left(b_{1} D_{1}+b_{2} D_{2}\right) g_{1}+\left(b_{1} D_{2}+b_{2} D_{1}\right) g_{2}\right]}{2\left(b_{1}^{2}-b_{2}^{2}\right)\left[2 \eta\left(b_{1}^{2}-b_{2}^{2}\right)-\left(b_{1} g_{1}+b_{2} g_{2}\right) g_{1}-\left(b_{1} g_{2}+b_{2} g_{1}\right) g_{2}\right]}>0, \\
& p_{d}^{c 2 *}-p_{d}^{c 1 *}=\frac{\left(b_{1} g_{2}+b_{2} g_{1}\right)\left[\left(b_{1} D_{1}+b_{2} D_{2}\right) g_{1}+\left(b_{1} D_{2}+b_{2} D_{1}\right) g_{2}\right]}{2\left(b_{1}^{2}-b_{2}^{2}\right)\left[2 \eta\left(b_{1}^{2}-b_{2}^{2}\right)-\left(b_{1} g_{1}+b_{2} g_{2}\right) g_{1}-\left(b_{1} g_{2}+b_{2} g_{1}\right) g_{2}\right]} 0 .
\end{aligned}
$$

It indicates that the cost of sales effort brings higher selling price, and the increased part is proportional to the sales effort: $p_{r}^{c 2 *}-p_{r}^{c 1 *}=\left(b_{1} g_{1}+b_{2} g_{2} / 2\left(b_{1}^{2}-b_{2}^{2}\right)\right) s^{c 2 *}$ and $p_{d}^{c 2 *}-p_{d}^{c 1 *}=\left(b_{1} g_{2}+b_{2} g_{1} / 2\left(b_{1}^{2}-b_{2}^{2}\right)\right) s^{c 2 *}$.

4.2. Decentralized Model with Sales Effort. This section considers that manufacturers, retailers, and third parties, respectively, make sales pricing decisions and collection pricing decisions to maximize their respective profits under the decentralized model with sales effort. Consider the supply chain under the manufacturer-led Stackelberg model. According to the profit function of retailer (22), profit function of manufacturer (23), and profit function of the third party (24), it has

$$
\begin{aligned}
& \widehat{\pi}_{r}\left(p_{r}, e_{r}, s\right)=\left(D_{1}-b_{1} p_{r}+b_{2} p_{d}+g_{1} s\right)\left(p_{r}-w\right)+\left[\begin{array}{ll}
(1-\alpha) \tau & D+\beta_{1} e_{r}-\beta_{2} e_{t}
\end{array}\right] \\
& \cdot\left(e-e_{r}\right)-\frac{1}{2} k\left[\begin{array}{ll}
(1-\alpha) \tau & D+\beta_{1} e_{r}-\beta_{2} e_{t}
\end{array}\right]^{2}-\frac{1}{2} \eta s^{2}, \\
& \widehat{\pi}_{d}\left(w, p_{d}\right)=\left(D_{1}-b_{1} p_{r}+b_{2} p_{d}+g_{1} s\right) w+\left(D_{2}-b_{1} p_{d}+b_{2} p_{r}+g_{2} s\right) p_{d} \\
& +\left(\beta_{1}-\beta_{2}\right)\left(c_{n}-c_{r}-e\right)\left(e_{r}+e_{t}\right)-(1-\tau) D c_{n}-\tau \quad D\left(c_{r}+e\right),
\end{aligned}
$$

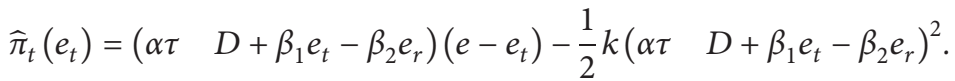

Proposition 4. When the market is under the decentralized model with sales effort, if the parameters of supply chain (31)-(33) satisfy the condition of $2 b_{1} \eta-g_{1}^{2}>0$ and
$4 b_{1}^{2} \eta\left[\left(2 b_{1}^{2}-b_{2}^{2}\right) \eta-b_{1} g_{1}^{2}-b_{2} g_{1} g_{2}\right]-\left(2 b_{1} b_{2} \eta-b_{2} g_{1}^{2}-b_{1} g_{1}\right.$ $\left.g_{2}\right)^{2}>0$, then there exists the unique optimal solution:

$$
\begin{aligned}
& p_{r}^{d 2 *}=\frac{b_{2} \eta\left(2 b_{1}^{2} \eta \varphi+D_{1} b_{1} \eta \phi\right)+\left(b_{1} \eta w-g_{1}^{2}\right)\left(2 D_{1} b_{1} \eta \kappa+\phi \varphi\right)}{\left(2 b_{1} \eta-g_{1}^{2}\right)\left(4 b_{1}^{2} \eta \kappa-\phi^{2}\right)}+\frac{D_{1} \eta}{2 b_{1} \eta-g_{1}^{2}}, \\
& s^{d 2 *}=\frac{b_{2} g_{1}\left(2 b_{1}^{2} \eta \varphi+D_{1} b_{1} \eta \phi\right)-b_{1} g_{1}\left(2 D_{1} b_{1} \eta \kappa+\phi \varphi\right)}{\left(2 b_{1} \eta-g_{1}^{2}\right)\left(4 b_{1}^{2} \eta \kappa-\phi^{2}\right)}+\frac{D_{1} g_{1}}{2 b_{1} \eta-g_{1}^{2}}, \\
& p_{d}^{d 2 *}=\frac{2 b_{1}^{2} \eta \varphi+D_{1} b_{1} \eta \phi}{4 b_{1}^{2} \eta \kappa-\phi^{2}}, \\
& w^{d 2 *}=\frac{2 D_{1} b_{1} \eta \kappa+\phi \varphi}{4 b_{1}^{2} \eta \kappa-\phi^{2}}, \\
& w^{d 2 *}=\frac{2 D_{1} b_{1} \eta \kappa+\phi \varphi}{4 b_{1}^{2} \eta \kappa-\phi^{2}}, \\
& \left.e_{r}^{d 2 *}=\frac{\beta_{1}\left(2+k \beta_{1}\right)\left[\beta_{1} e-\left(1+k \beta_{1}\right)(1-\alpha) \tau \quad D\right]+\beta_{2}\left(1+k \beta_{1}\right)\left[\beta_{1} e-\left(1+k \beta_{1}\right) \alpha \tau\right.}{\beta_{1}^{2}\left(2+k \beta_{1}\right)^{2}-\beta_{2}^{2}\left(1+k \beta_{1}\right)^{2}} \quad D\right] \\
& e_{t}^{d 2 *}=\frac{\beta_{1}\left(2+k \beta_{1}\right)\left[\beta_{1} e-\left(1+k \beta_{1}\right) \alpha \tau \quad D\right]+\beta_{2}\left(1+k \beta_{1}\right)\left[\beta_{1} e-\left(1+k \beta_{1}\right)(1-\alpha) \tau\right.}{\beta_{1}^{2}\left(2+k \beta_{1}\right)^{2}-\beta_{2}^{2}\left(1+k \beta_{1}\right)^{2}},
\end{aligned}
$$

where $\varphi=D_{1}\left(b_{2} \eta+g_{1} g_{2}\right)+D_{2}\left(2 b_{1} \eta-g_{1}^{2}\right), \kappa=\left(2 b_{1}^{2}-b_{2}^{2}\right)$ $\eta-b_{1} g_{1}^{2}-b_{2} g_{1} g_{2}$, and $\phi=2 b_{1} b_{2} \eta-b_{2} g_{1}^{2}-b_{1} g_{1} g_{2}$.
Proof. For the retailer and the third party, according to the profit functions of the retailer and the third party (31) and 
(33), taking the first-order derivatives of $\hat{\pi}_{r}\left(p_{r}, e_{r}, s\right)$ and $\widehat{\pi}_{t}\left(e_{t}\right)$ along the retail price $p_{r}$, the collecting price of retailer $e_{r}$, sales effort $s$, and the collecting price of the third party $e_{t}$, respectively, we could obtain

$$
\begin{aligned}
& \frac{\partial \hat{\pi}_{r}\left(p_{r}, e_{r}, s\right)}{\partial p_{r}}=-2 b_{1} p_{r}+b_{2} p_{d}+b_{1} w+g_{1} s+D_{1}, \\
& \frac{\partial \hat{\pi}_{r}\left(p_{r}, e_{r}, s\right)}{\partial s}=g_{1} p_{r}-g_{1} w-\eta s, \\
& \frac{\partial \hat{\pi}_{r}\left(p_{r}, e_{r}, s\right)}{\partial e_{r}}=-\beta_{1}\left(2+k \beta_{1}\right) e_{r}+\beta_{2}\left(1+k \beta_{1}\right) e_{t}+\beta_{1} e-\left(1+k \beta_{1}\right)(1-\alpha) \tau \quad D, \\
& \frac{\partial \hat{\pi}_{t}\left(e_{t}\right)}{\partial e_{t}}=\beta_{2}\left(1+k \beta_{1}\right) e_{r}-\beta_{1}\left(2+k \beta_{1}\right) e_{t}+\beta_{1} e-\left(1+k \beta_{1}\right) \alpha \tau \quad D .
\end{aligned}
$$

Based on the condition of proposition $2 b_{1} \eta-g_{1}^{2}>0$, it obtains that

$$
\begin{aligned}
& p_{r}^{d 2 *}=\frac{b_{2} \eta p_{d}+\left(b_{1} \eta w-g_{1}^{2}\right) w+D_{1} \eta}{2 b_{1} \eta-g_{1}^{2}} \\
& s^{d 2 *}=\frac{b_{2} g_{1} p_{d}-b_{1} g_{1} w+D_{1} g_{1}}{2 b_{1} \eta-g_{1}^{2}},
\end{aligned}
$$

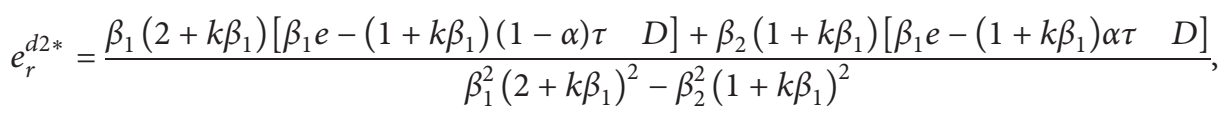

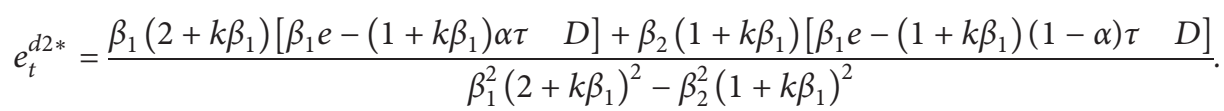

Substitute the $p_{r}^{d 2 *}, s^{d 2 *}, e_{r}^{d 2 *}$, and $e_{t}^{d 2 *}$ into profit function (32), for the manufacturer, taking the first-order derivatives of $\hat{\pi}_{d}\left(p_{d}, w\right)$ along the direct price $p_{d}$ and wholesale price $w$, and we could obtain

$$
\begin{aligned}
& \frac{\partial \pi_{d}\left(p_{d}, w\right)}{\partial p_{d}}=\frac{-2\left[\left(2 b_{1}^{2}-b_{2}^{2}\right) \eta-b_{1} g_{1}^{2}-b_{2} g_{1} g_{2}\right]}{2 b_{1} \eta-g_{1}^{2}} p_{d}+\frac{2 b_{1} b_{2} \eta-b_{2} g_{1}^{2}-b_{1} g_{1} g_{2}}{2 b_{1} \eta-g_{1}^{2}} w+\frac{D_{1}\left(b_{2} \eta+g_{1} g_{2}\right)+D_{2}\left(2 b_{1} \eta-g_{1}^{2}\right)}{2 b_{1} \eta-g_{1}^{2}} \\
& \frac{\partial \pi_{d}\left(p_{d}, w\right)}{\partial w}=\frac{2 b_{1} b_{2} \eta-b_{2} g_{1}^{2}-b_{1} g_{1} g_{2}}{2 b_{1} \eta-g_{1}^{2}} p_{d}-\frac{2 b_{1}^{2} \eta}{2 b_{1} \eta-g_{1}^{2}} w+\frac{D_{1} b_{1} \eta}{2 b_{1} \eta-g_{1}^{2}}
\end{aligned}
$$

The Hessian matrix is given as

$$
H^{d 2}=\left(\begin{array}{cc}
-2\left[\left(2 b_{1}^{2}-b_{2}^{2}\right) \eta-b_{1} g_{1}^{2}-b_{2} g_{1} g_{2}\right] & 2 b_{1} b_{2} \eta-b_{2} g_{1}^{2}-b_{1} g_{1} g_{2} \\
2 b_{1} b_{2} \eta-b_{2} g_{1}^{2}-b_{1} g_{1} g_{2} & -2 b_{1}^{2} \eta
\end{array}\right)
$$


TABLE 2: Table of basic data.

\begin{tabular}{lccccccccccccc}
\hline Parameter & $b_{1}$ & $b_{2}$ & $\tau$ & $c_{n}$ & $c_{r}$ & $\eta$ & $\alpha$ & $\beta_{1}$ & $\beta_{2}$ & $k$ & $e$ & $g_{1}$ & $g_{2}$ \\
\hline Value & 0.7 & 0.2 & 0.9 & 50 & 1 & 1 & 0.51 & 0.9 & 0.2 & 0.1 & 5 & 0.8 & 0.5 \\
\hline
\end{tabular}

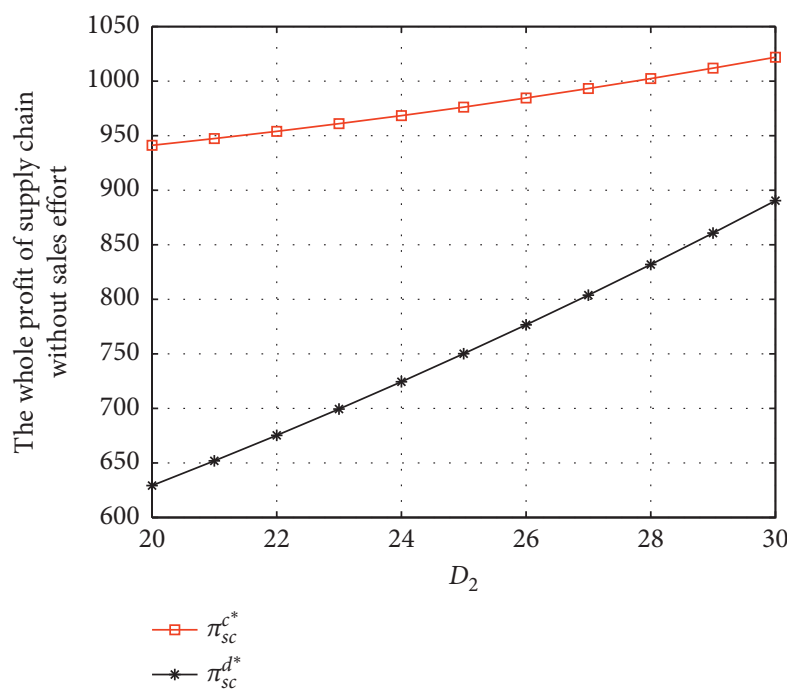

(a)

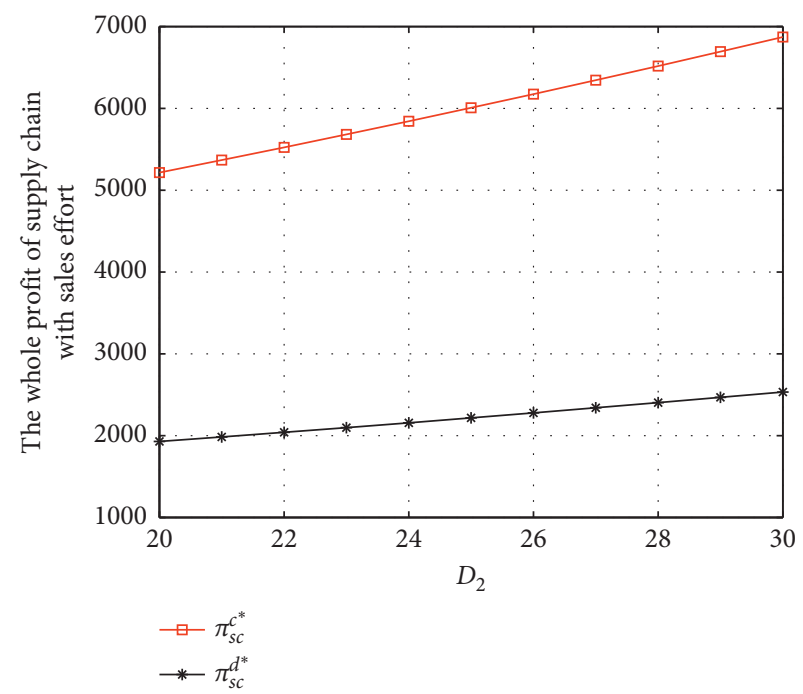

(b)

Figure 2: The optimal profit of whole supply chain under the centralized and decentralized model.

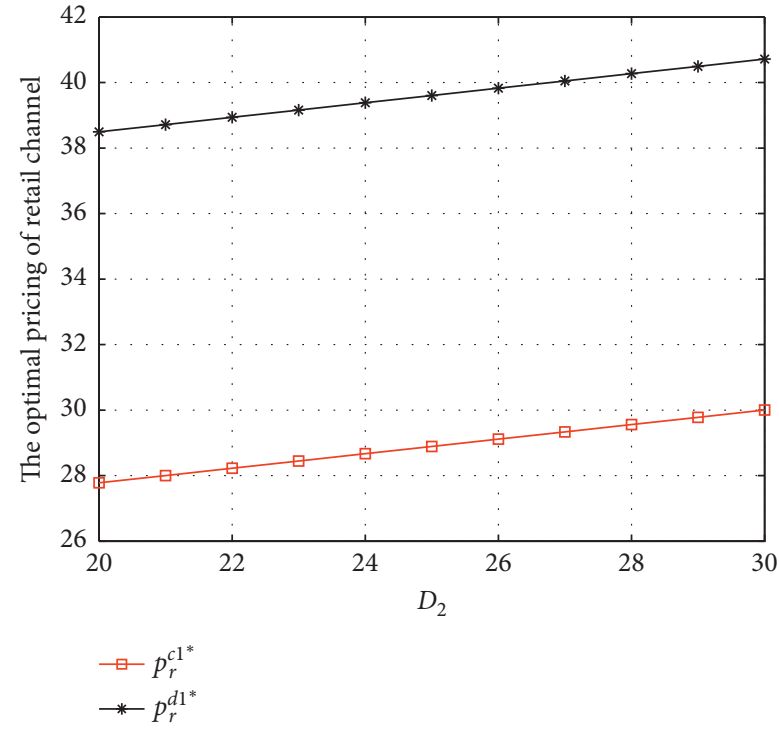

(a)

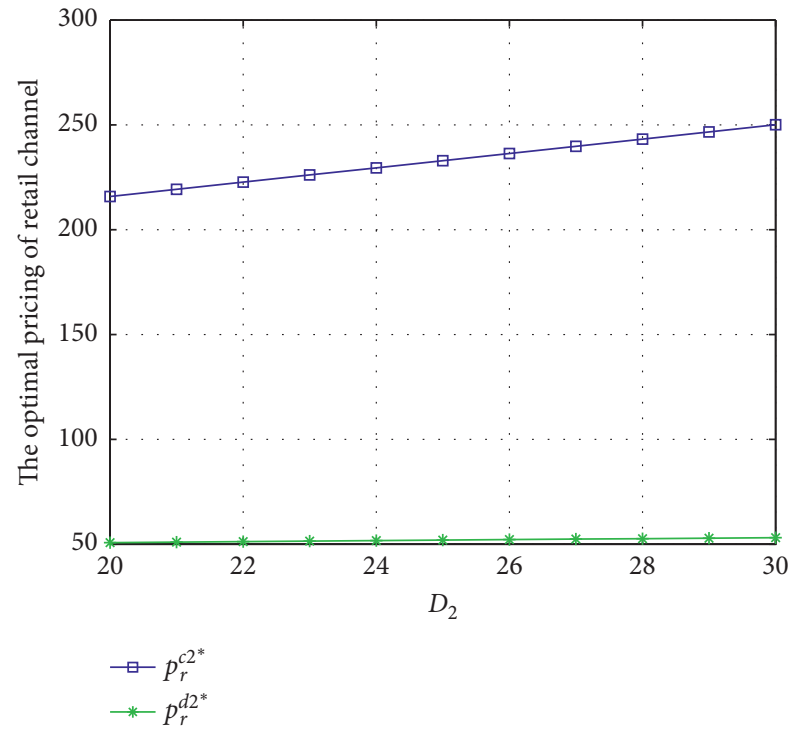

(b)

FIgURE 3: The optimal retail selling price under the centralized and decentralized model.

According to the condition of Proposition $4,4 b_{1}^{2} \eta\left[\left(2 b_{1}^{2}\right.\right.$ $\left.\left.-b_{2}^{2}\right) \eta-b_{1} g_{1}^{2}-b_{2} g_{1} g_{2}\right]-\left(2 b_{1} b_{2} \eta-b_{2} g_{1}^{2}-b_{1} g_{1} g_{2}\right)^{2}>0$, we know $\left|H^{d 2}\right|=4 b_{1}^{2} \eta\left[\left(2 b_{1}^{2}-b_{2}^{2}\right) \quad \eta-b_{1} g_{1}^{2}-b_{2} g_{1} g_{2}\right]-\left(2 b_{1}\right.$ $\left.b_{2} \eta-b_{2} g_{1}^{2}-b_{1} g_{1} g_{2}\right)^{2}>0$. Therefore, the profit function $\widehat{\pi}_{D}\left(p_{d}, w\right)$ is joint concave on $p_{d}$ and $w$. The optimal solution could be obtained by solving the first-order condition as follows: 


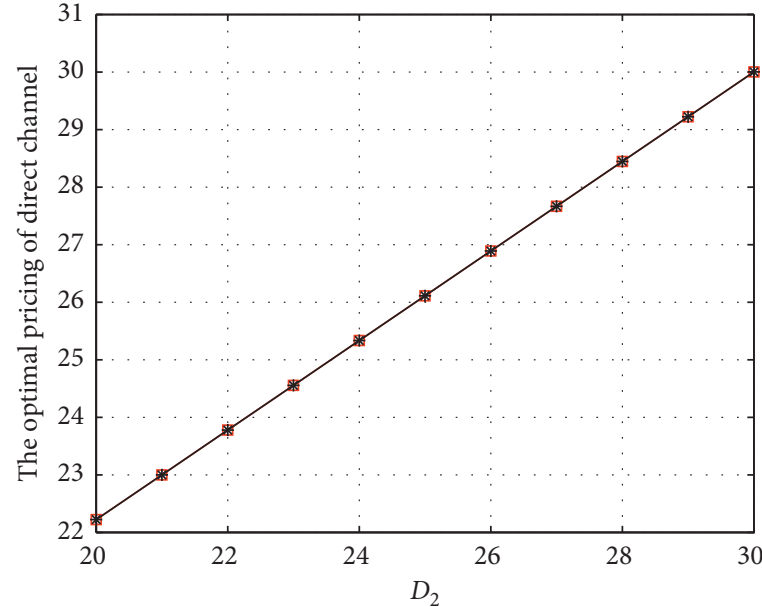

$\square p_{d}^{c 1^{*}}$
$\rightarrow * p^{d 1^{*}}$

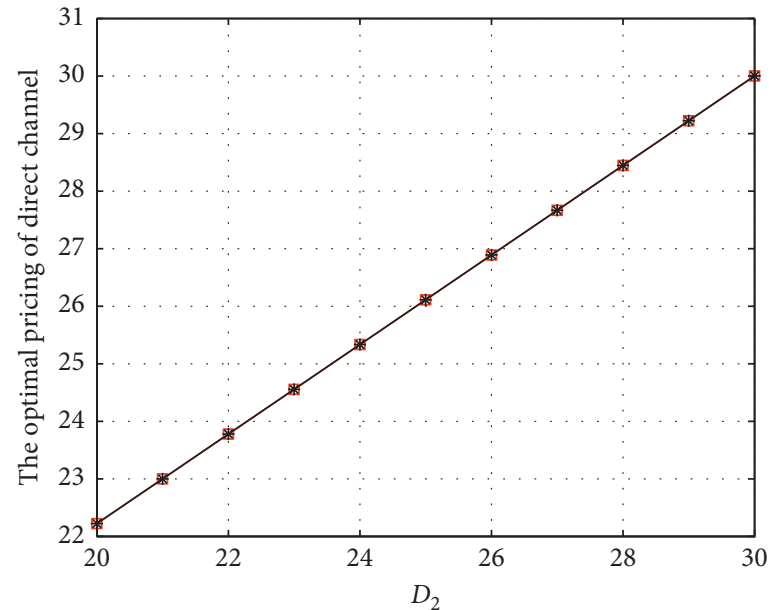

$\rightarrow p_{d}^{c 2^{*}}$

$\rightarrow p_{d}^{d 2^{*}}$

(a)

(b)

FIgURE 4: The optimal direct selling price under the centralized and decentralized model.

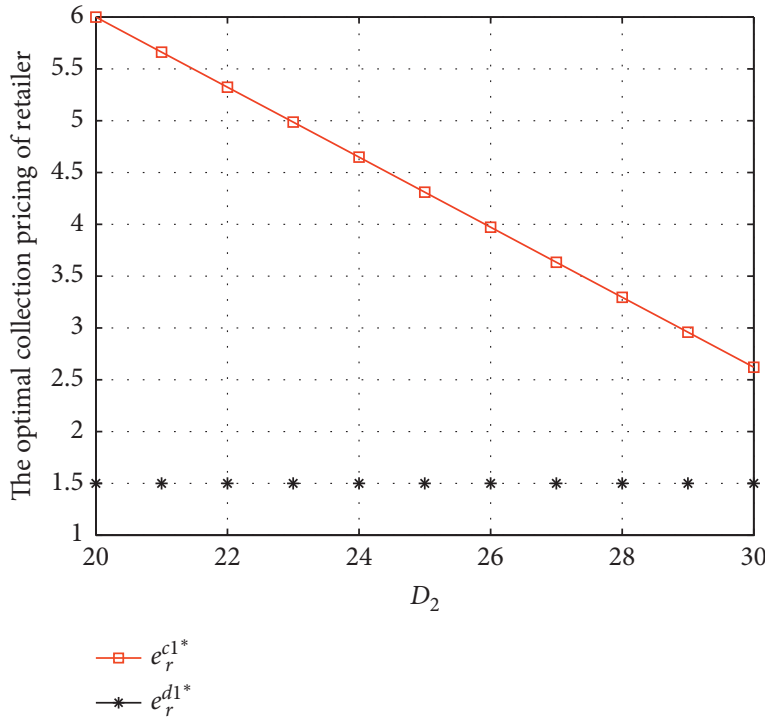

(a)

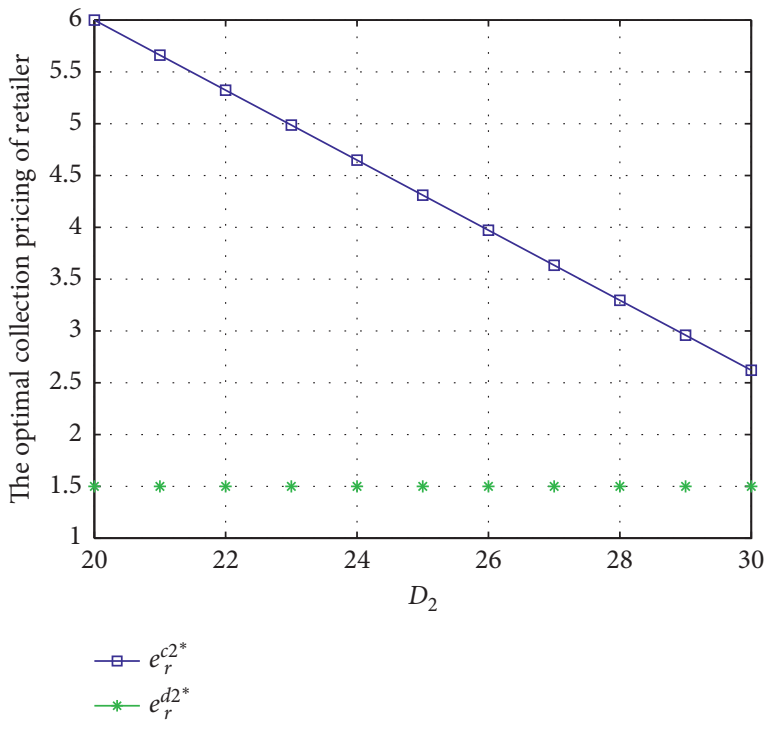

(b)

FIgURE 5: The optimal collection price of the retailer under the centralized and decentralized model.

$$
\begin{aligned}
p_{d}^{d 2 *}= & \frac{2 b_{1}^{2} \eta\left[D_{1}\left(b_{2} \eta+g_{1} g_{2}\right)+D_{2}\left(2 b_{1} \eta-g_{1}^{2}\right)\right]+D_{1} b_{1} \eta\left(2 b_{1} b_{2} \eta-b_{2} g_{1}^{2}-b_{1} g_{1} g_{2}\right)}{\left.4 b_{1}^{2} \eta\left[\left(2 b_{1}^{2}-b_{2}^{2}\right) \eta-b_{1} g_{1}^{2}-b_{2} g_{1} g_{2}\right]\right]-\left(2 b_{1} b_{2} \eta-b_{2} g_{1}^{2}-b_{1} g_{1} g_{2}\right)^{2}}, \\
w^{d 2 *}= & \frac{2 D_{1} b_{1} \eta\left[\left(2 b_{1}^{2}-b_{2}^{2}\right) \eta-b_{1} g_{1}^{2}-b_{2} g_{1} g_{2}\right]}{4 b_{1}^{2} \eta\left[\left(2 b_{1}^{2}-b_{2}^{2}\right) \eta-b_{1} g_{1}^{2}-b_{2} g_{1} g_{2}\right]-\left(2 b_{1} b_{2} \eta-b_{2} g_{1}^{2}-b_{1} g_{1} g_{2}\right)^{2}} \\
& +\frac{\left(2 b_{1} b_{2} \eta-b_{2} g_{1}^{2}-b_{1} g_{1} g_{2}\right)\left[D_{1}\left(b_{2} \eta+g_{1} g_{2}\right)+D_{2}\left(2 b_{1} \eta-g_{1}^{2}\right)\right]}{4 b_{1}^{2} \eta\left[\left(2 b_{1}^{2}-b_{2}^{2}\right) \eta-b_{1} g_{1}^{2}-b_{2} g_{1} g_{2}\right]-\left(2 b_{1} b_{2} \eta-b_{2} g_{1}^{2}-b_{1} g_{1} g_{2}\right)^{2}} .
\end{aligned}
$$

The proof is completed. 


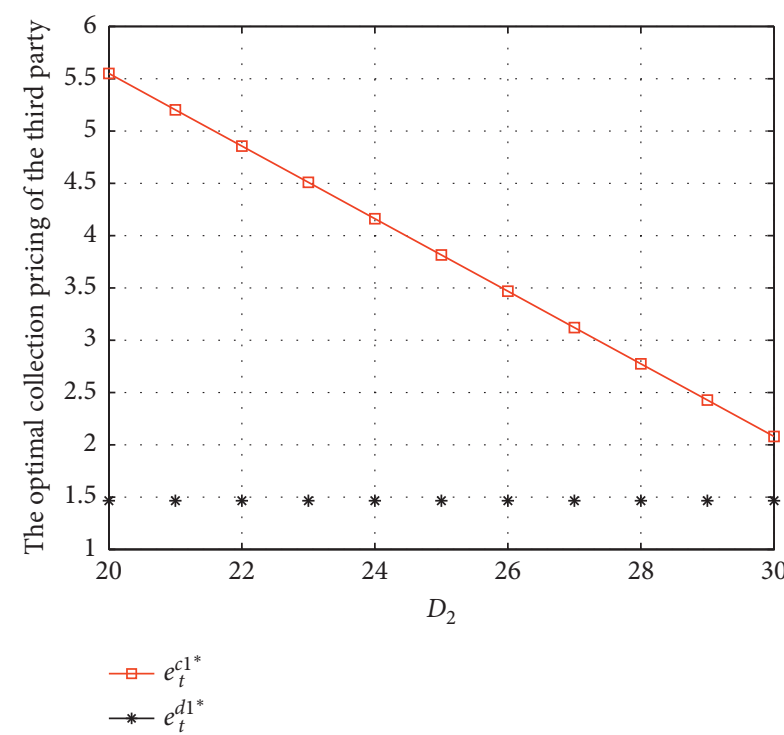

(a)

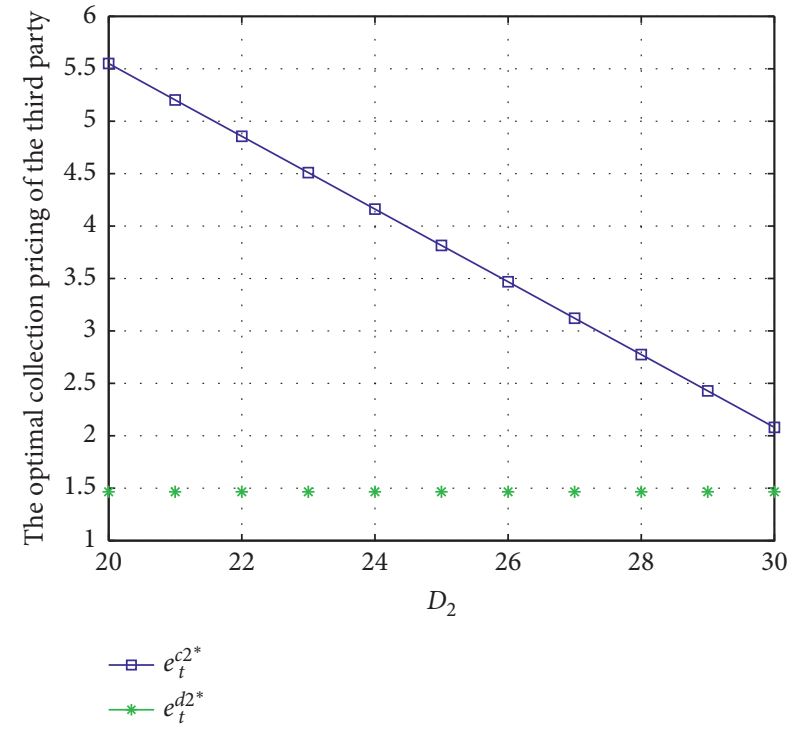

(b)

FIgURE 6: The optimal collection price of the third party under the centralized and decentralized model.

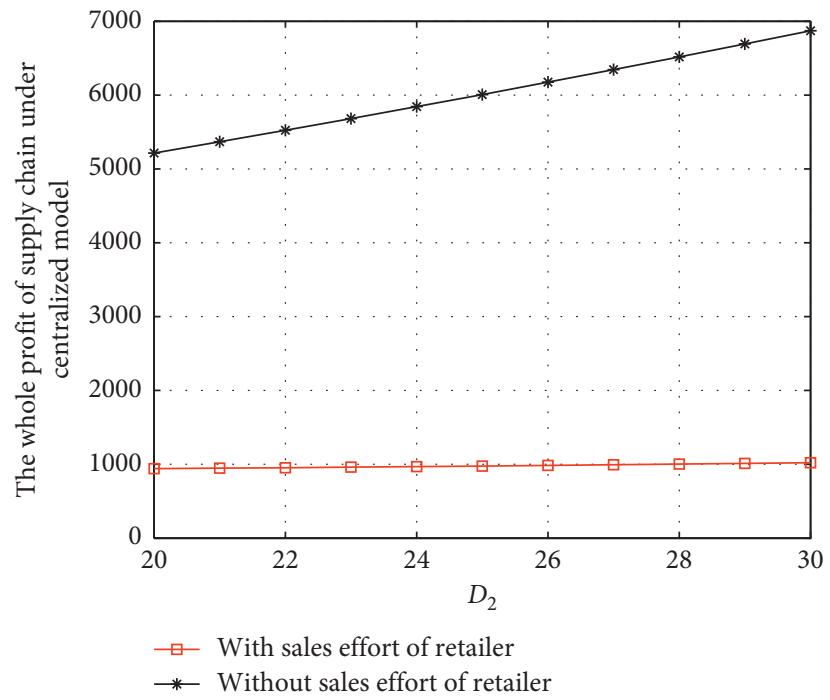

Figure 7: The optimal profit of whole supply chain with sales effort under the centralized model.

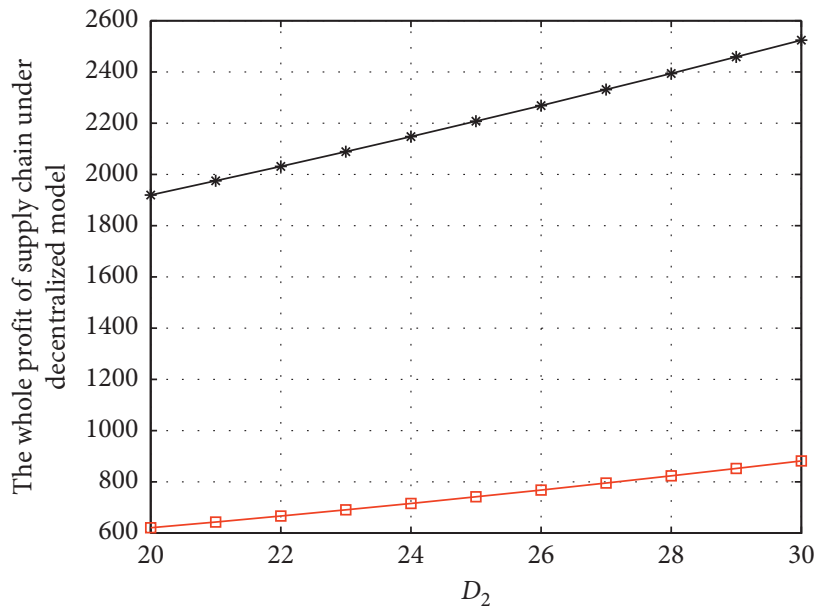

$\square$ With sales effort of retailer

$\rightarrow$ Without sales effort of retailer

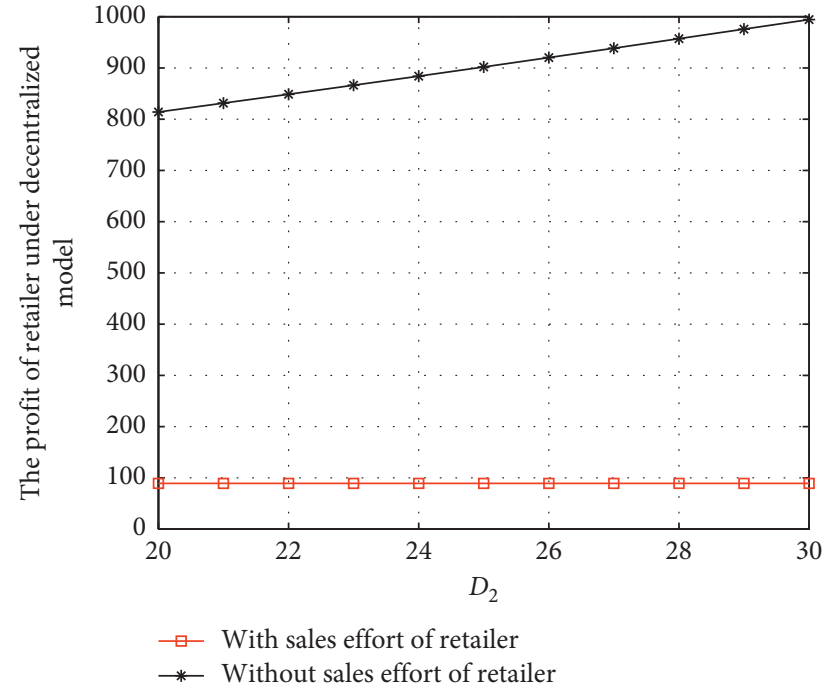

(b)

Figure 8: Continued. 


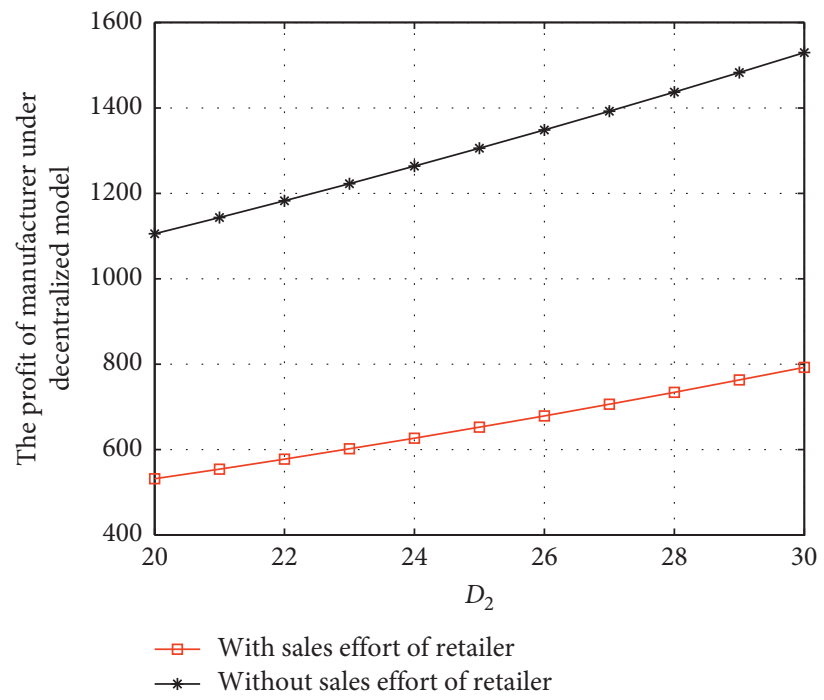

(c)

FIGURE 8: The optimal profit with and without sales effort under the decentralized model.

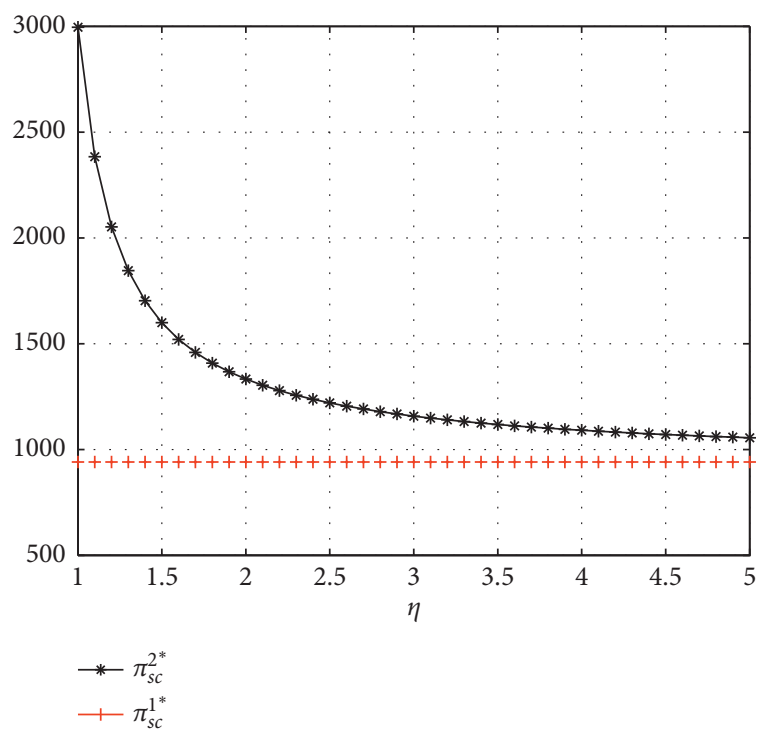

(a)

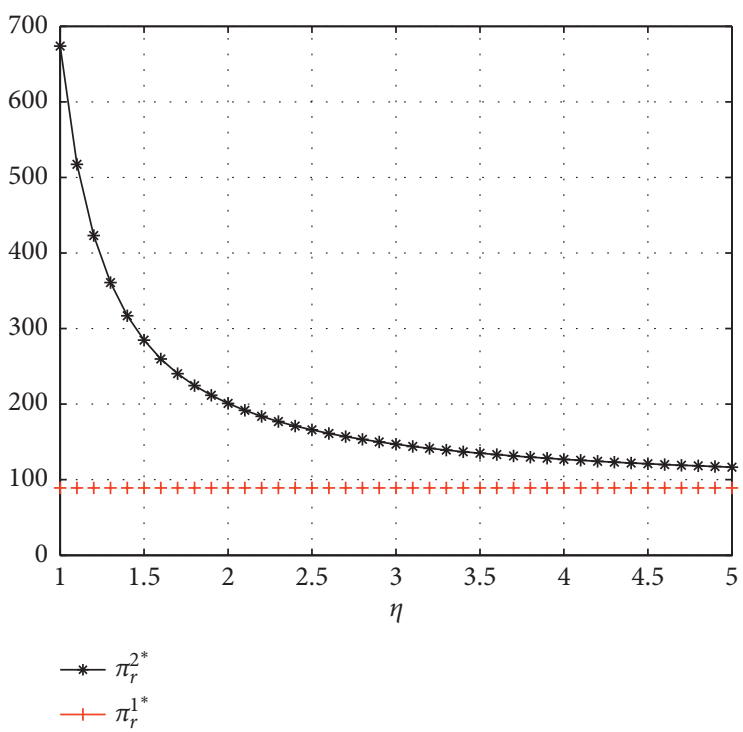

(b)

Figure 9: Continued. 


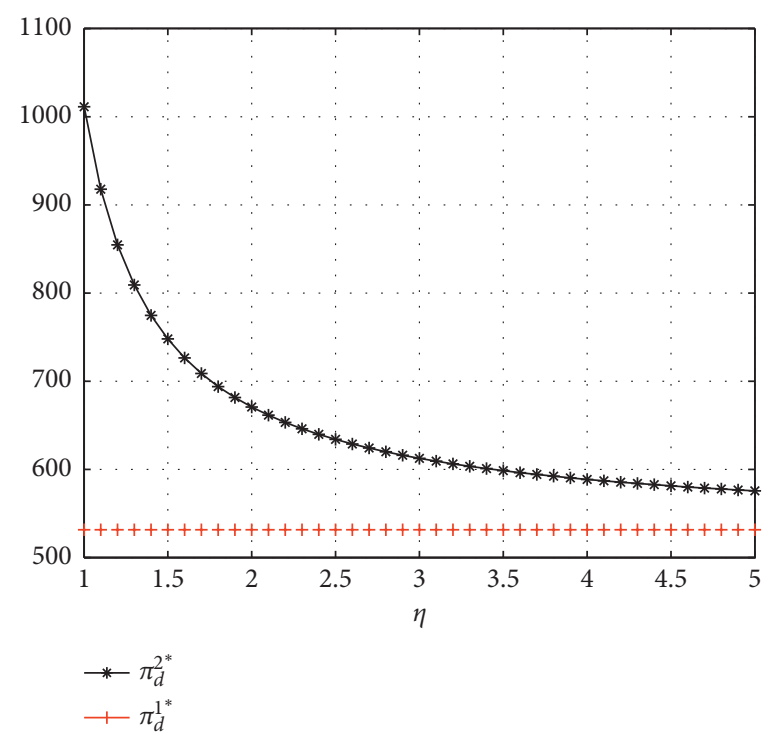

(c)

FIGURE 9: The effect of the value of $\eta$ on profit under the centralized model and decentralized model.

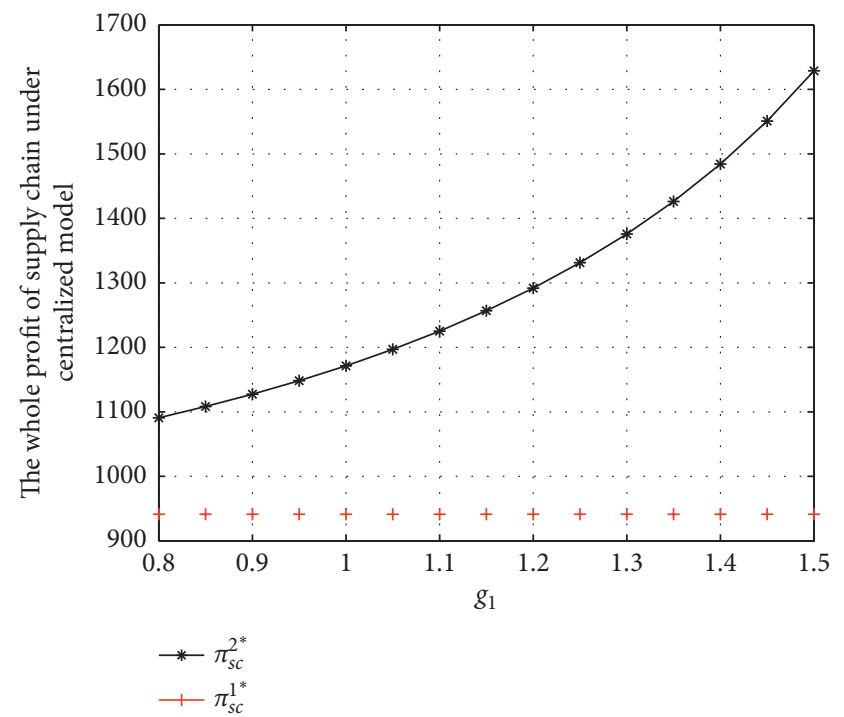

(a)

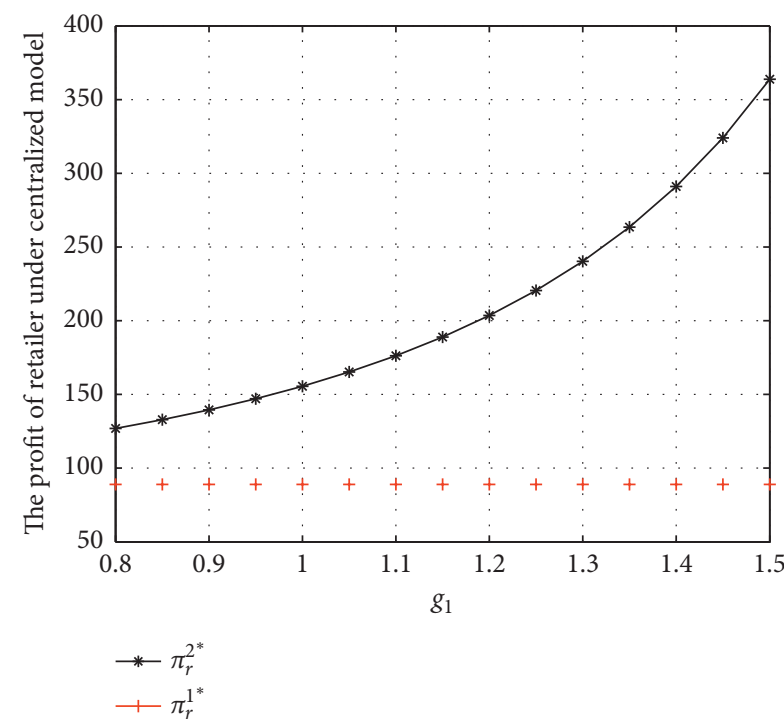

(b)

FIgURe 10: Continued. 


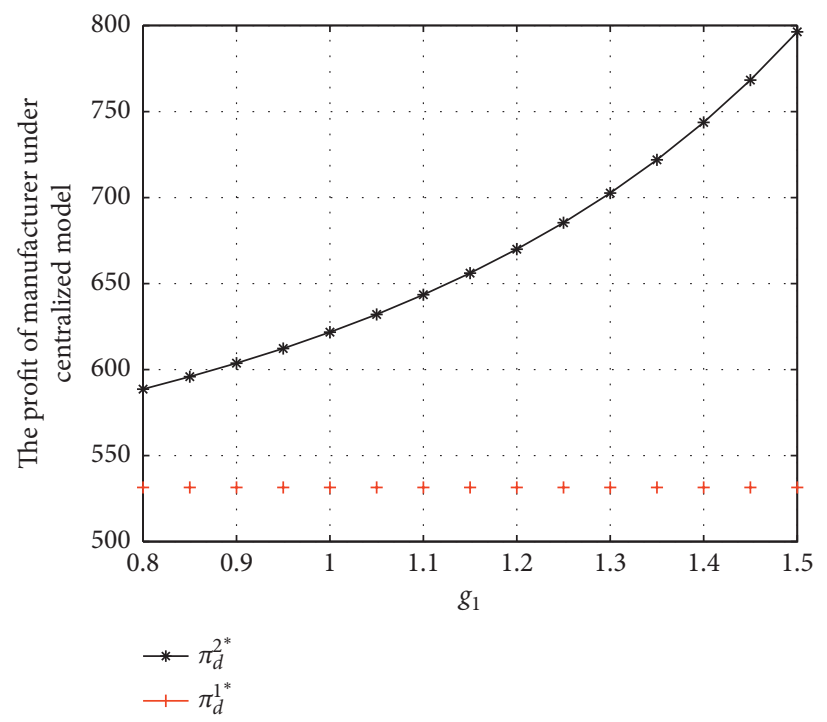

(c)

Figure 10: The effect of the value of $g_{1}$ on profit under the centralized model and decentralized model.

Remark 2. In the study of [19], analysis for strategy of the closed-loop supply chain with dual recycling channel was carried out. Based on game theory, the authors characterized the supply chain performance in terms of the pricing decisions and the recycling strategies for both the decentralized and the centralized channel scenarios. On the contrary, the supply chain channel strategy with quality and marketing effort-dependent demand was considered in [22]. Different from the existing results, this paper provides four scenarios for different decision models and with or without sales effort. The optimal solution is derived and comparison for four scenarios is given in this paper.

\section{Numerical Illustrations}

This section carries on numerical example analysis of the proposed propositions by comparing the optimal decision of four propositions. Sensitivity analysis are provided to illustrate the impact of supply chain parameters on system performance. Table 2 shows the basic data.

\subsection{Centralized Model and Decentralized Model. By com-} paring the optimal solution under the centralized model and decentralized model with and without sales effort, it could be concluded from Figure 2 that the profit under the centralized model is always higher than the profit under the decentralized model. Therefore, Pareto improvement could be achieved by the revenue sharing contract.

Figures 3 and 4 show that, with the increase of the market scale, retail selling price and direct selling price will increase. It is easy to understand that the increase of the market scale leads to higher demand. Under the decentralized model, the retail selling price is higher than the retail selling price under the centralized model. The existence of wholesale price brings this result under the decentralized model. Figure 4 shows that the direct selling price of the manufacturer is independent of the decentralized model or centralized model. Figures 5 and 6 are the collection price of the retailer and the third party, respectively. With the increase of the market scale, the collection price would decrease.

5.2. The Effect of Sales Effort on Optimal Pricing and Profit. The demand for different channels depends on the choice of consumers, and the sales effort of the retailer has an important influence on the market. In the process of operation and management, managers should pay attention to the channel preference of customers. As shown in Figure 7, sales effort of the retailer under the centralized model could increase the whole profit of supply chain.

It can be seen from Figure 8 that the sales effort of the retailer under the decentralized model could increase the whole profit of the supply chain and the profit of the manufacturer and retailer, respectively.

5.3. Sensitivity Analysis. This section discusses the effect of the marginal cost coefficient of sales effort on profit. It can be found from Figure 9 that when $\eta$ increases, each member's profit decreases and the rate of change decreases.

It can be found from Figure 10 that when $g_{1}$ increases, the profits of each supply chain members all increase and the rate of change increases.

\section{Conclusions}

This paper studies the optimal pricing of the dual-channel supply chain with the third-party product recovery and sales effort. First of all, for the general case under the centralized and decentralized model, the optimal selling pricing of the direct channel and retail channel in the forward supply chain and the optimal collection pricing of the retail channel and the third party in the backward supply chain are discussed. 
Then, the optimal pricing strategy with sales effort under the centralized and decentralized model is provided and analyzed. Finally, the comparative analysis of four situations is carried out by numerical results. The effect of sales effort and decision-making model on the optimal pricing, demand, and profit is demonstrated.

\section{Data Availability}

The data used to support the findings of this study are available from the corresponding author upon request.

\section{Conflicts of Interest}

The authors declare that they have no conflicts of interest.

\section{Acknowledgments}

This work was supported by the National Natural Science Foundation of China under Grants 61773004 and 61803056 and in part by the Natural Science Foundation Project of Chongqing under Grant cstc2018jcyjAX0365 and Program of Chongqing Innovation Team Project in University under Grant CXTDX201601022.

\section{References}

[1] V. V. Agrawal, A. Atasu, and K. Van Ittersum, "Remanufacturing, third-party competition, and consumers' perceived value of new products," Management Science, vol. 61, no. 1, pp. 60-72, 2015.

[2] G. Ferrer and J. M. Swaminathan, "Managing new and remanufactured products," Management Science, vol. 52, no. 1, pp. 15-26, 2006.

[3] J. Ding, W. Chen, and W. Wang, "Production and carbon emission reduction decisions for remanufacturing firms under carbon tax and take-back legislation," Computers \& Industrial Engineering, vol. 143, Article ID 106419, 2020.

[4] M. Pazoki and G. Zaccour, "A mechanism to promote product recovery and environmental performance," European Journal of Operational Research, vol. 274, no. 2, pp. 601-614, 2019.

[5] W. Kerr and C. Ryan, "Eco-efficiency gains from remanufacturing," Journal of Cleaner Production, vol. 9, no. 1, pp. 75-81, 2001.

[6] L. Wu, L. Liu, and Z. Wang, "Competitive remanufacturing and pricing strategy with contrast effect and assimilation effect," Journal of Cleaner Production, vol. 257, Article ID 120333, 2020.

[7] A. Yenipazarli, "Managing new and remanufactured products to mitigate environmental damage under emissions regulation," European Journal of Operational Research, vol. 249, no. 1, pp. 117-130, 2016.

[8] T.-M. Choi, Y. Chen, and S. H. Chung, "Online-offline fashion franchising supply chains without channel conflicts: choices on postponement and contracts," International Journal of Production Economics, vol. 215, pp. 174-184, 2019.

[9] C.-H. Wu, "OEM product design in a price competition with remanufactured product," Omega, vol. 41, no. 2, pp. 287-298, 2013.

[10] D. Krass, T. Nedorezov, and A. Ovchinnikov, "Environmental taxes and the choice of green technology," Production and Operations Management, vol. 22, no. 5, pp. 1035-1055, 2013.
[11] D. Hammond and P. Beullens, "Closed-loop supply chain network equilibrium under legislation," European Journal of Operational Research, vol. 183, no. 2, pp. 895-908, 2007.

[12] X. Chang, H. Xia, H. Zhu, T. Fan, and H. Zhao, "Production decisions in a hybrid manufacturing-remanufacturing system with carbon cap and trade mechanism," International Journal of Production Economics, vol. 162, pp. 160-173, 2015.

[13] M. E. Ferguson and L. B. Toktay, "The effect of competition on recovery strategies," Production and Operations Management, vol. 15, no. 3, pp. 351-368, 2006.

[14] L. Liu, Z. Wang, L. Xu, X. Hong, and K. Govindan, "Collection effort and reverse channel choices in a closed-loop supply chain," Journal of Cleaner Production, vol. 144, pp. 492-500, 2017.

[15] R. Kleber, M. Reimann, G. C. Souza, and W. Zhang, "Twosided competition with vertical differentiation in both acquisition and sales in remanufacturing," European Journal of Operational Research, vol. 284, no. 2, pp. 572-587, 2020.

[16] N. M. Modak, N. Modak, S. Panda, and S. S. Sana, "Analyzing structure of two-echelon closed-loop supply chain for pricing, quality and recycling management," Journal of Cleaner Production, vol. 171, pp. 512-528, 2018.

[17] S. Panda, N. M. Modak, and L. E. Cárdenas-Barrón, "Coordinating a socially responsible closed-loop supply chain with product recycling," International Journal of Production Economics, vol. 188, pp. 11-21, 2017.

[18] N. M. Modak and P. Kelle, "Managing a dual-channel supply chain under price and delivery-time dependent stochastic demand," European Journal of Operational Research, vol. 272, no. 1, pp. 147-161, 2019.

[19] S. He, D. Zhu, Y. Chen, X. Liu, Y. Chen, and X. Wang, "Application and problems of emergy evaluation: a systemic review based on bibliometric and content analysis methods," Ecological Indicators, vol. 114, Article ID 106304, 2020.

[20] Y. Zhou, F. Hu, and Z. Zhou, "Pricing decisions and social welfare in a supply chain with multiple competing retailers and carbon tax policy," Journal of Cleaner Production, vol. 190, pp. 752-777, 2018.

[21] A. Atasu, M. Sarvary, and L. N. Van Wassenhove, "Remanufacturing as a marketing strategy," Management Science, vol. 54, no. 10, pp. 1731-1746, 2008.

[22] S. Agrawal, R. K. Singh, and Q. Murtaza, "A literature review and perspectives in reverse logistics," Resources, Conservation and Recycling, vol. 97, pp. 76-92, 2015.

[23] R. C. Savaskan and L. N. Van Wassenhove, "Reverse channel design: the case of competing retailers," Management Science, vol. 52, no. 1, pp. 1-14, 2006.

[24] M. Huang, M. Song, L. H. Lee, and W. K. Ching, "Analysis for strategy of closed-loop supply chain with dual recycling channel," International Journal of Production Economics, vol. 144, no. 2, pp. 510-520, 2013.

[25] X. Hong, Z. Wang, D. Wang, and H. Zhang, "Decision models of closed-loop supply chain with remanufacturing under hybrid dual-channel collection," The International Journal of Advanced Manufacturing Technology, vol. 68, no. 5-8, pp. 1851-1865, 2013.

[26] T. A. Taylor, "Supply chain coordination under channel rebates with sales effort effects," Management Science, vol. 48, no. 8, pp. 992-1007, 2002.

[27] P. Ma, H. Wang, and J. Shang, "Supply chain channel strategies with quality and marketing effort-dependent demand," International Journal of Production Economics, vol. 144, no. 2, pp. 572-581, 2013. 
[28] H. Yang, J. Chen, X. Chen, and B. Chen, "The impact of customer returns in a supply chain with a common retailer," European Journal of Operational Research, vol. 256, no. 1, pp. 139-150, 2017.

[29] G. Hua, S. Wang, and T. C. E. Cheng, "Price and lead time decisions in dual-channel supply chains," European Journal of Operational Research, vol. 205, no. 1, pp. 113-126, 2010.

[30] D. Ghosh and J. Shah, "A comparative analysis of greening policies across supply chain structures," International Journal of Production Economics, vol. 135, no. 2, pp. 568-583, 2012. 